Research Article

\title{
Numerical Investigation of Bundled RC Column under Impact Load
}

\author{
Abreha Abay (iD) and Temesgen Wondimu $(\mathbb{D}$ \\ Department of Civil Engineering, Collage of Architecture and Civil Engineering, Addis Ababa Science and Technology University, \\ Addis Ababa1230, Ethiopia \\ Correspondence should be addressed to Abreha Abay; aabay3013@gmail.com
}

Received 27 February 2021; Revised 12 July 2021; Accepted 9 August 2021; Published 24 August 2021

Academic Editor: Zhongguo John Ma

Copyright ( 2021 Abreha Abay and Temesgen Wondimu. This is an open access article distributed under the Creative Commons Attribution License, which permits unrestricted use, distribution, and reproduction in any medium, provided the original work is properly cited.

\begin{abstract}
Dynamic impact load has an extensive application area in civil engineering, including highway, military, and marine structures. Many researchers have studied the performance of reinforced concrete (RC) columns under impact load. However, very limited work has been conducted on the effect of bundle reinforced concrete (BRC) columns subjected to lateral impact load. In this study, to examine the behavior of RC columns under impact load, numerical simulations of one with normal reinforcement distribution and three different bundles of reinforced concrete column specimens have been conducted using an explicit finite element (FE) analysis. In addition to the bundle reinforcement distribution, the parameters considered in the study are impact scenarios, impact velocity, pure axial load, and impact locations. From the numerical analysis, it has been found that bundling of longitudinal reinforcement does not only improve the impact capacity but also stabilizes the fluctuating response of impacted reinforced concrete columns. Both peak impact force and maximum lateral displacements of impacted BRC columns increase with increasing initial impact velocity. The numerical results also show that pure axial load slightly improved the impact capacity of the BRC columns. Finally, while the global failure of the RC column governs the response of repeatedly impacted BRC columns, failure characteristics of the single impacted columns are associated with local concrete damage at the impact zone.
\end{abstract}

\section{Introduction}

The axial load behaviors of the reinforced concrete (RC) column have been widely studied under static loads. During their service life, RC compression members can also experience extreme dynamic loading conditions such as wind, earthquake, blast, and lateral impact loads [1]. As compared to the static load and other dynamic loads, less attention has been given to assess the dynamic impact load resisting capacities of these structural elements [2].

Impact load is a sudden dynamic load that occurs with the colliding of one body against the other. It is characterized by transferring stored energy from the impactor to the structural element within a short period of time. The impacted structure absorbs transferred energy by its deformation. During sudden energy transfer, the impacted structure develops high stress and finally deformation.

The behavior of RC structures subjected to impact is different from that caused due to static load. Compared to the static loads, the strain rate of given material under lateral impact load is high. Consequently, the RC structural members subjected to impact load are significantly influenced not only by the structural strength, which resists the impact load, but also by the energy absorption capacity of the system. The design and analysis of these structures under impact load require a detailed understanding of the performance and material properties of the RC structural elements [3]. In addition to behaviors of the structural 
element, parameters associated with the impactor such as impact velocity, impactor size, and mass have also a great influence on the capacity of the RC structure.

Designing strong columns saves RC building from complete failure and reduces the consequence of loss and fatality due to impact load. But, as the number of stories in high-rise buildings increases, the total load that is transferred to the $\mathrm{RC}$ column increases. This results in a large amount of steel reinforcement bar to be provided based on the design requirements which led to congested steel reinforcement bar distribution. Sometimes, the placement of steel bars based on clear spacing recommended by design codes is not an operational choice. In such a case, there are mainly two options to overcome these difficulties: (a) increase the cross-sectional area of the structural element (i.e., $\mathrm{RC}$ column) and/or the size of the reinforcement bar, and (b) bundle the longitudinal reinforcement bars into groups of two, three, or four bars. The first option increases the total cost of the project, and it is not feasible from the standpoint of space and aesthetic requirements. In contrast, bundling of the longitudinal reinforcement bar is relatively advantageous in reducing the cost of the project and saving spacing (i.e., provide slender column), and it importantly ensures easier placement and vibration of wet concrete by reducing bar congestion. However, the interaction between bundled reinforcement bars and the surrounding concrete decreases and thus leads to wide cracks $[4,5]$. Moreover, unlike static loads that result in a ductile flexural failure mode, lateral impact-loaded structural members failed by brittle shear mode. To minimize such drawbacks, it is necessary to research and understand how bundled RC columns can achieve the desired performance under impact load.

Several researchers [6-11] examined experimentally and numerically the behavior of RC structures subjected to lateral impact load. Wang and Morgenthal [6] and Demartino et al. [12] conducted experimental and numerical tests to study the impact capacity of RC columns. They concluded that an increase in impact velocity leads to an increase in peak load value and duration of impact load, and the shear damage was reduced by increasing the transverse shear reinforcement ratio. Tin et al. [13] studied the dynamic performance of RC bridge columns under vehicle collision. Finally, they observed that the equivalent static force from vehicle collision recommended by current design standards ignored the dynamic behaviors of the structures and hence inaccurately predicted the impact forces.

Sha and Hong [14] assessed a pendulum impact test to understand the effect of CFRP strengthened RC pier under barge impact load. Their results reveal that the application of CFRP composite wrapping on the RC pier improves the impact load capacity by increasing impact resistance and reducing maximum displacement. Dabbagh and Nosoudi [15] reported that the increase in column size and concrete strength enhances the dynamic impact load capacities by reducing lateral displacement of the RC column. They also observed that providing a small corner radius for square and rectangular RC columns increases the ductility and lateral displacement capacities of the columns. Paul [16], Liu et al. [7], and Xie et al. [17] studied that, in the case of low impact velocity, axially loaded RC columns are laterally stiff with small defection, quick peak response, and greater dumping. Besides, they observed that since the impact load was transferred to the support reaction, mid-span deflections of the columns do not fluctuate with time.

Fan et al. [11] investigated the axial behavior of circular RC columns after low-velocity impact. Fan et al. [10] proposed numerically predicting efficiently the flexural and shear capacities of RC beams and columns subjected to low impact loading. Although these and other previous researchers [11, 18, 19] carried out experimental tests and numerical simulations of RC columns subjected to impact loads, their studies mainly focused on single impact with low impact velocity. From the literature, it is observed that limited studies were conducted to evaluate the impact performance of the BRC column under repeated impact load. Therefore, the main objective of this study is to numerically investigate the behaviors of the BRC column under both single and repeated lateral impact loads. The impact response of four groups of RC column specimens with different parameters, namely, impact velocity, axial load, and impact locations, is examined. The results monitored including impact force, lateral displacements, and damage modes are presented and discussed.

\section{Finite Element Modeling}

2.1. Description of the Study. In this study, numerical simulations of the RC columns with different cases have been developed. The accuracy of the numerical modeling is validated by using previous experimental tests conducted by Sha and Hong [14]. During their test, impact load was increased continuously by elevating the pendulum impact ring with an increment of five degrees in each subsequent impact condition until the specimen failed. However, on the numerical modeling, the initial impact velocities of the impactor were determined from the elevated pendulum system using the conservation of mechanical energy.

To understand the impact behavior of BRC columns, several square RC column specimens were modeled. Based on longitudinal steel reinforcement bar distribution, four groups of RC column specimens, namely, group 1 (BC-1), group 2 (BC-2), group 3 (BC-3), and group 4 (BC-4), were considered. The specimens under group 1 denote the column section with a normal distribution of steel reinforcement bars whereas as shown in Figure 1 group 2, group 3, and group 4 BRC column specimens represent two, three, and four bundle steel reinforcement distributions, respectively. Each RC column specimen consists of a $400 \times 400 \mathrm{~mm}$ square $3 \mathrm{~m}$ high column. As described in Table 1, all specimens were modeled with the same grades of steel and concrete materials. In each BRC column, reinforcement bars with diameters of $20 \mathrm{~mm}, 8 \mathrm{~mm}$, and $6 \mathrm{~mm}$ were employed for longitudinal, shear stirrup, and bundle stirrup reinforcements, respectively.

The nomenclature for the study parameters (i.e., bundle reinforcement, impact velocity, axial load, and rigid mass impactor) is described as shown in Figure 2. Furthermore, the basic parameters considered in this study are 

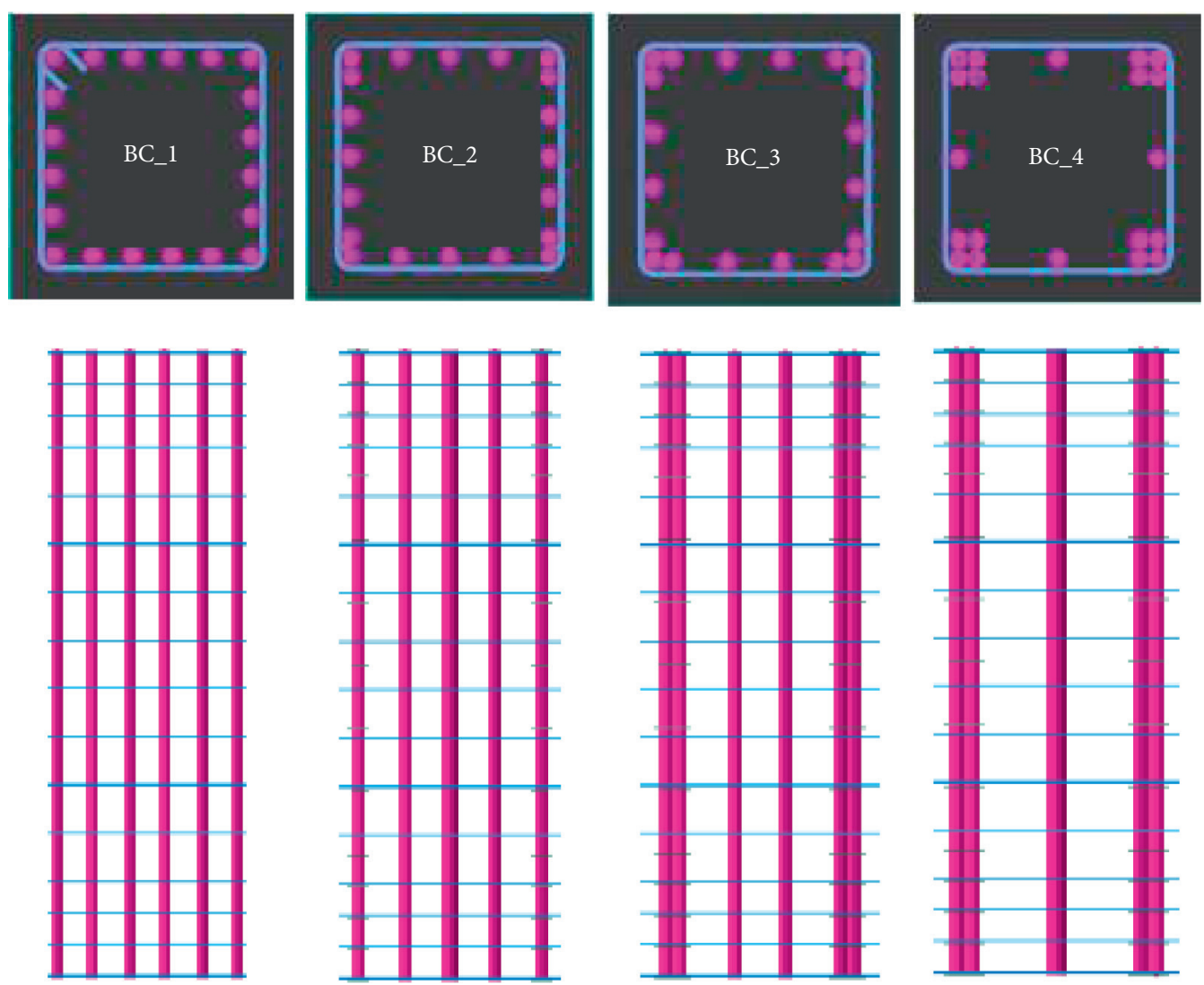

FIGURE 1: Cross-sectional and longitudinal BRC column specimen detailing.

TABLe 1: Material properties for concrete and steel reinforcement.

\begin{tabular}{|c|c|c|c|c|c|c|}
\hline \multicolumn{7}{|c|}{ Concrete } \\
\hline & $\begin{array}{l}\text { Density } \\
(\mathrm{kg} / \mathrm{m} 3)\end{array}$ & Elastic modulus (GPa) & Poisson's ratio $(\nu)$ & $\begin{array}{c}\text { Compressive strength, } \\
f_{c}(\mathrm{MPa})\end{array}$ & $\begin{array}{c}\text { Tensile strength, } \\
f_{\mathrm{ctm}}(\mathrm{MPa})\end{array}$ & Ultimate strain (\%) \\
\hline & 2400 & 32.84 & 0.2 & 38 & 2.89 & 0.35 \\
\hline \multicolumn{7}{|c|}{ Steel reinforcement bars } \\
\hline & $\begin{array}{l}\text { Density, } \\
\rho\left(\mathrm{kg} / \mathrm{m}^{3}\right) \\
\end{array}$ & Poisson ratio, $v$ & $\begin{array}{c}\text { Elastic modulus, } \\
E_{s}(\mathrm{GPa}) \\
\end{array}$ & Yield stress, $f_{y}(\mathrm{MPa})$ & Yield strain, $\varepsilon_{y}$ & Ultimate stress, $f_{u}(\mathrm{MPa})$ \\
\hline Main bar & 7850 & 0.3 & 200 & 500 & 0.0025 & 695 \\
\hline Stirrup & 7850 & 0.3 & 200 & 460 & 0.0023 & 655 \\
\hline
\end{tabular}

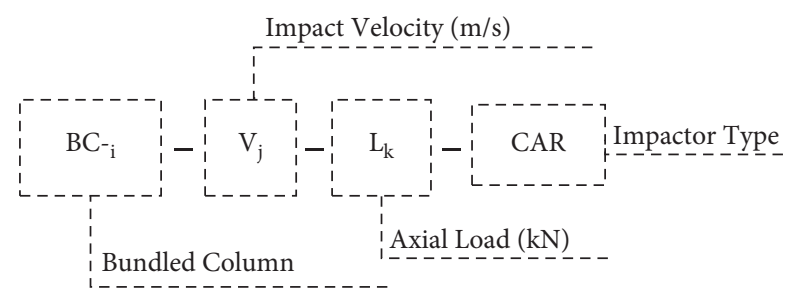

Figure 2: Nomenclature of study specimens.

summarized in Figure 3. During the FE simulation, the impact velocities, axial loads, and impact locations are considered for each bundle reinforced column separately.

As shown in Figure 3, to understand the effect of axial load on impact capacity of BRC column, axial loads of $0 \%$, $14 \%, 21 \%$, and $42 \%$ of the axial column capacity $\left(P_{\text {capacity }}\right)$ have been employed. $P_{\text {capacity }}$ represents the axial capacity of the RC column under concentric axial load which is given by

$$
P_{\text {capacity }}=b_{1} f_{c}^{\prime}\left(A_{g}-A_{s}\right)+A_{s} f_{y}
$$

where $\beta_{1} f_{c}^{\prime}$ is the maximum concrete stress permitted in column design, $A_{g}$ is the gross area of the section, $f_{y}$ is the yield strength of steel reinforcement, and $A_{\text {st }}$ denotes the total area of reinforcement bars in the section.

2.2. Finite Element Discretization. The numerical model of $\mathrm{RC}$ pier under impact test was simulated using an FE analysis package Abaqus explicit. Steel reinforcement bar and concrete material are modeled by a two-node linear 3D truss (T3D2) element and a 3D eight-node linear brick element with reduced integration and hourglass control 

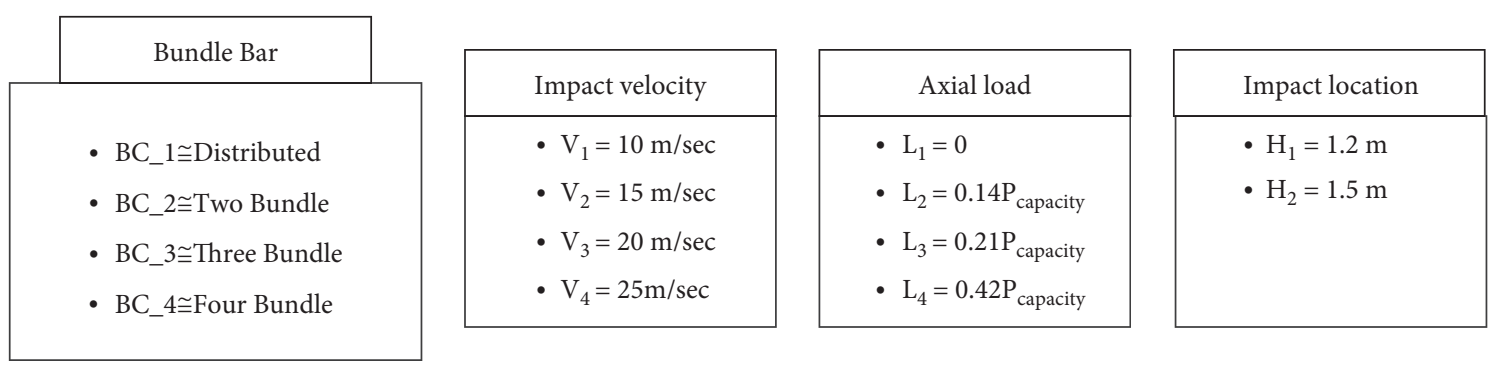

Figure 3: Summary of study parameters.

(C3D8R), respectively. The pendulum impact ring is also modeled with a four-node $3 \mathrm{D}$ bilinear rigid quadrilateral (R3D4) element. As shown in Figure 4, surface to surface (explicit) contact algorism was implemented for the interaction between RC column and impactor ring. The impactor face and RC column surface were considered as master and slave surfaces, respectively. The interaction between concrete and reinforcement bar is simulated with the embedded region constraint. This interaction mechanism approximately simulates the load transfer between the host region (i.e., concrete) and embedded region (reinforcement) bar to have a perfect bond.

\subsection{Constitutive Material Model}

2.3.1. Concrete. In Abaqus, the quasibrittle nature of concrete can be modeled by three different approaches, namely, smeared crack model (SCM), brittle cracking model (BCM), and concrete damaged plasticity (CDP) model [20]. Each constitutive model provides a general competence for modeling typical concrete structures. The application and specific advantages of these models depend on the analysis type being conducted. Smeared crack model is intended for applications in which the concrete structure is subjected to primarily monotonic loadings at low confining pressures. In SCM, concrete crack is treated as the most important aspect of concrete material behavior modeling. Then again, BCM is required for applications where concrete behavior is dominated by tensile cracking. In this model, concrete compressive failure is not important and is treated as linear elastic. The concrete damaged plasticity (CDP) model is recommended for modeling concrete under monotonic, cyclic, or dynamic loading. This method can describe the complete inelastic behavior of concrete in both compression and tension. For this reason, the CDP model is adopted in this study to characterize concrete material.

As shown in Figure 5, the CDP model considers that the main failure mechanisms of concrete are tensile cracking and compressive crushing [20]. In general, the CDP model is a plasticity-based constitutive model that requires defining strain rate decomposition, stress stain relation, stiffness degradation mechanisms associated with each failure mode, hardening rule, flow rule, and stiffness recovery effects during load reversals [20].

For strain-dependent models in CDP formulation, the total strain rate is usually assumed to be the sum of elastic and plastic strain rates as described in

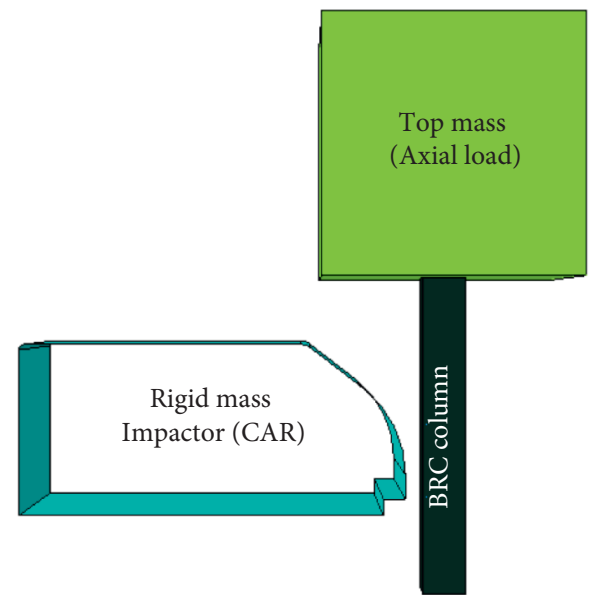

Figure 4: Schematic representation of the model.

$$
\dot{\varepsilon}=\dot{\varepsilon}^{e l}+\dot{\varepsilon}^{p l}
$$

where $\dot{\varepsilon}$ is the total strain rate, $\dot{\varepsilon}^{\text {el }}$ is the elastic part of the strain rate, and $\dot{\varepsilon}^{p i}$ is the plastic part of the strain rate. The general stress-strain relationship of concrete in the CDP model can be expressed using

$$
\begin{aligned}
& \sigma_{t}=D_{o}^{e l}\left(1-d_{t}\right)\left(\varepsilon_{t}-\varepsilon_{t}^{p l}\right), \\
& \sigma_{c}=D_{o}^{e l}\left(1-d_{c}\right)\left(\varepsilon_{c}-\varepsilon_{c}^{p l}\right),
\end{aligned}
$$

where $\sigma$ is the stress tensor, $\varepsilon$ is the strain tensor, $\varepsilon^{p l}$ is the plastic strain tensor, $D_{o}^{e l}$ is the initial (i.e., undamaged) elastic stiffness, $d$ is the scalar stiffness degradation variable, and the subscripts $t$ and $c$, respectively, refer to the tension and compression zones of concrete.

2.4. Concrete Compressive Behavior. Under compressive loading concrete exhibits a nonlinear stress-strain response with a significant irreversible strain upon unloading. This growth of uncovered deformation during loading is described by its elastic limit and postyield hardening of the material. As shown in Figure 5(a), the uniaxial compressive stress-strain curve of concrete is linear until the value of the initial yield point, $\sigma_{c o}$, is reached. This point has been taken as the initial plastic point, and the initial plastic strain at this point is considered as zero [20, 21]. Increased loading beyond the yield point causes the concrete to behave plastically. The stress continues to increase with further strain 


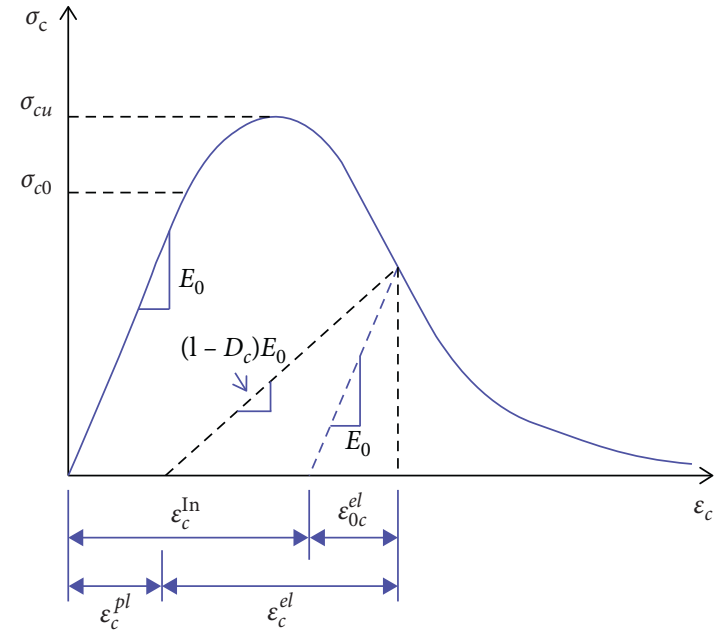

(a)

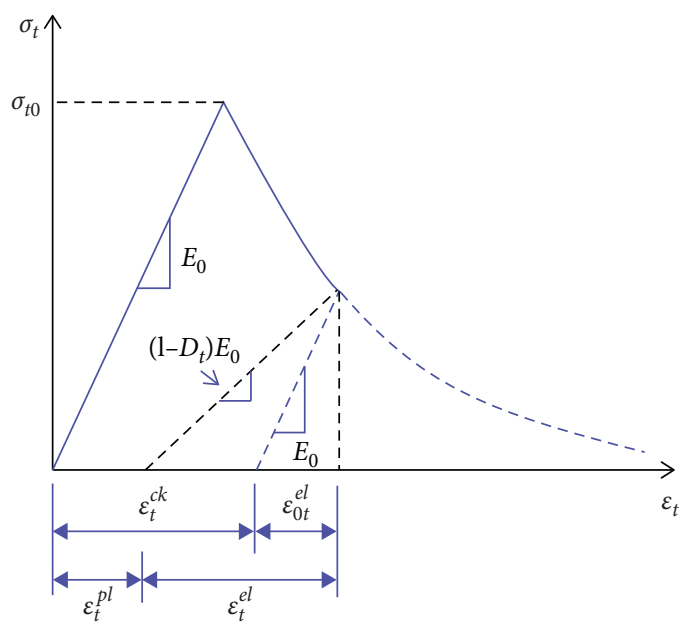

(b)

FIGURE 5: CDP model of concrete material [20]. (a) Compressive behavior. (b) Tensile behavior.

hardening up to the ultimate stress $\sigma_{c u}$. Loading further than the peak ultimate stress causes a negative slope of the stressstrain curve that is referred to as strain softening.

The CDP model allows defining the uniaxial compressive behavior of concrete in terms of inelastic (crashing) strain, $\widetilde{\mathcal{E}}_{c}^{i n}$. This compressive strain can be defined as the total strain $\left(\varepsilon_{c}\right)$ minus the elastic strain $\left(\varepsilon_{o c}^{e l}\right)$ corresponding to the undamaged material, given by

$$
\tilde{\varepsilon}_{c}^{i n}=\varepsilon_{c}-\varepsilon_{o c}^{e l}=\varepsilon_{c}-\frac{\sigma_{c}}{D_{o}} .
$$

After determining the inelastic strain and damage parameter, Abaqus automatically converts these values to plastic strain using

$$
\widetilde{\varepsilon}_{c}^{p l}=\widetilde{\varepsilon}_{c}^{i n}-\frac{d_{c} \sigma_{c}}{\left(1-d_{c}\right) D_{o}} .
$$

As shown in Figure 6(a), using the compressive strength of concrete, different concrete compressive stress-strain models were reproduced [22-26]. From these concrete compressive material models, the Eurocode stress-strain relation for nonlinear analysis which is defined by equation (6) and depicted in Figure 6(b) provides very good agreement with the numerical model validation of the existing study [22].where $\sigma_{c}$ is the concrete compressive stress, $\eta=$ $\varepsilon_{c} / \varepsilon_{c 1}$ with $\varepsilon_{c 1}=0.7 f_{\mathrm{cm}}^{0.13}$ is the strain at peak stress, and $k=$ $1.05 E_{\mathrm{cm}}\left|\varepsilon_{c 1}\right| / f_{\mathrm{cm}}$ is the plasticity number. Furthermore, $E_{\mathrm{cm}}$ and $f_{\mathrm{cm}}$ are the secant modulus of elasticity and the mean value compressive strength of concrete.

$$
\frac{\sigma_{c}}{f_{c m}}=\frac{k \eta-\eta^{2}}{1+(k-2) \eta}
$$

2.5. Concrete Tensile Behavior. When a concrete specimen is subjected to uniaxial tension, the stress-strain response is linear until the onset of microcracking due to failure stress, $\sigma_{\text {to }}$ is reached. As shown in Figure 5(b), after this point, the failure stress induces strain localization and the microcracks that are represented with a softening stress-strain response. This postfailure tension behavior of concrete can be modeled with tension stiffening that allows defining the strain-softening behavior of cracked concrete and the effect of reinforcement concrete interaction. In the CDP model, the tension stiffening of concrete can be specified by either postfailure stress-strain relation or fracture energy cracking criterion. In this study, to describe the tensile behavior of cracked concrete section, the fracture energy concept which is expressed as stress versus crack opening is employed $[27,28]$ (see Figure $7(\mathrm{a}))$. The tensile damage variable $\left(d_{t}\right)$ versus crack opening curves of concrete, which is computed using equation (7), is also described in Figure 7(b) [27].

$$
d_{t}=1-\frac{\sigma_{c} E_{c}^{-1}}{\varepsilon_{t}^{p l}\left(1 / b_{t}-1\right)+\sigma_{t} E_{c}^{-1}} .
$$

2.6. Steel Reinforcement Bar. Unlike concrete, steel reinforcement is a homogeneous material that does not depend on time and environmental conditions. Therefore, a single stress-strain relationship is sufficient to define the steel material properties needed in nonlinear FE analysis. As recommended by Kachlakev et al. [29] and shown in Figure 8 , the nonlinear part of steel behavior can be modeled as an elastic-perfectly plastic material using a strain hardening ratio of 0.01 . Furthermore, the strain rate effect on the dynamic strength of concrete and steel materials is considered based on the CEB-FIP model code $[28,30]$.

\section{Result and Discussions}

3.1. Validation of Nonlinear FE Models. As shown in Figure 9, numerical input parameters including material definitions (refer Table 2), boundary conditions, and geometric properties of the numerical models were adopted from the previous experimental test conducted by Sha and Hong [14]. 


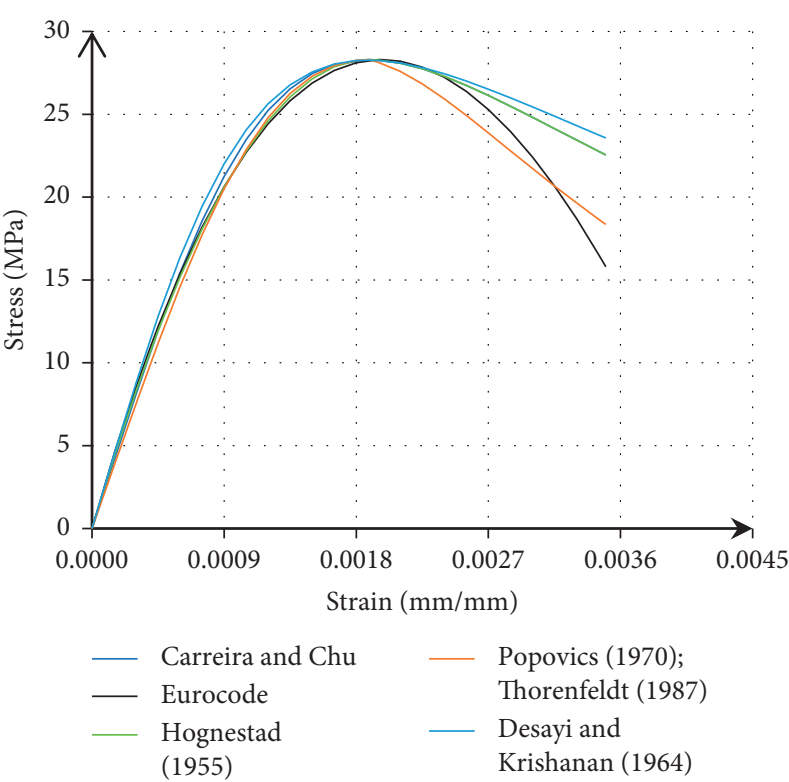

(a)

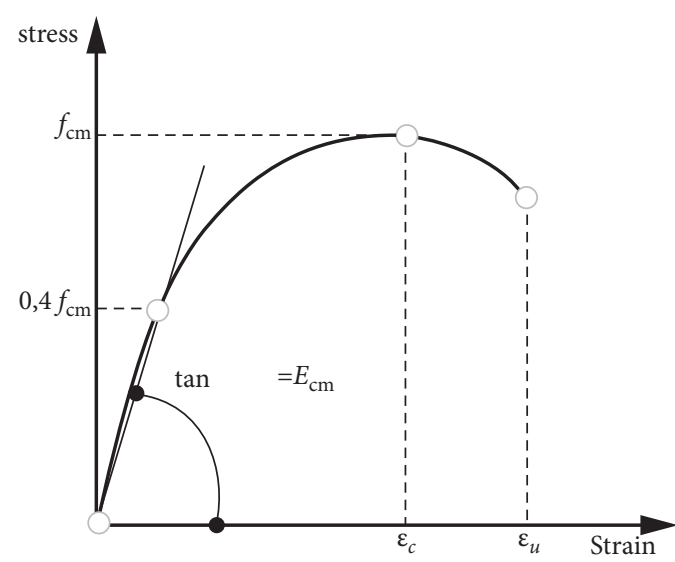

(b)

Figure 6: Concrete compressive stress-strain relation. (a) Common concrete models. (b) Eurocode based [22].

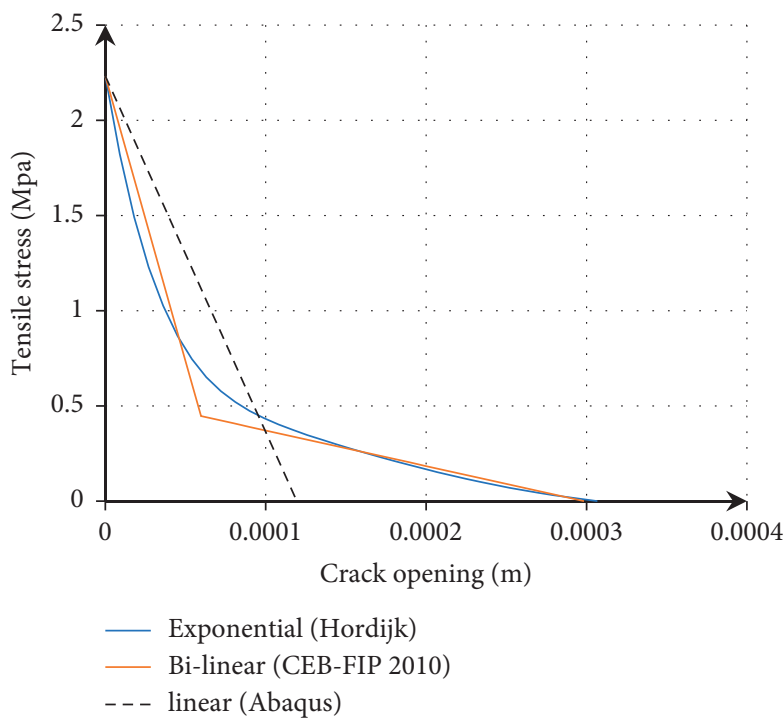

(a)

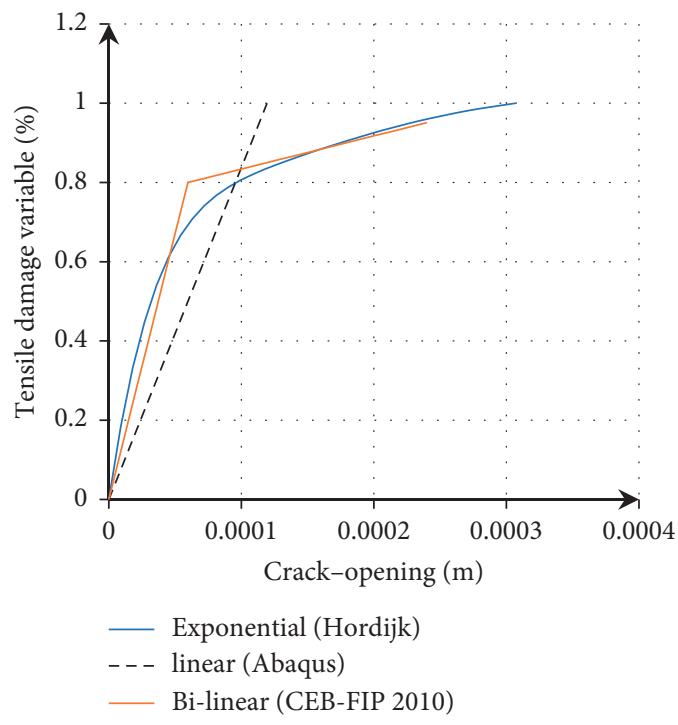

(b)

Figure 7: Postfailure concrete tensile behavior. (a) Tensile stress-crack opening curves. (b) Tensile damage versus crack opening curve.

Then, after the nonlinear FE analysis, impact forces versus time history outputs and damage modes were compared with the experimental results. As shown in Figure 10, the comparison of the numerical analysis and experimental results revealed that in all impact cases the peak impact force results of FE models fit well with the experimental test. For example, under the first impact, the impact force-history shows a peak impact force of $11.28 \mathrm{kN}$ and $12.07 \mathrm{kN}$ for numerical and experimental tests, respectively.

However, there are some deviations beyond the peak impact force, especially in the $3^{\text {rd }}$ and $4^{\text {th }}$ impact cases. This may be because the energy losses on experimental tests due to factors, such as rebar slippage and pendulum hinge friction, are not considered in the nonlinear FE simulations. During numerical analysis, slippage of steel reinforcement and concrete was ignored by assuming perfect bond interaction. Furthermore, after dynamic impact simulation has been conducted using Abaqus/Explicit, the unbalanced dynamic forces (i.e., the postimpact vibrations) of impacted members need to be at equilibrium. To obtain static configuration after the dynamic impact, it is recommended to transfer the result obtained with Abaqus/Explicit to Abaqus/ Standard. But, in this study, only Abaqus/Explicit simulation was employed. 


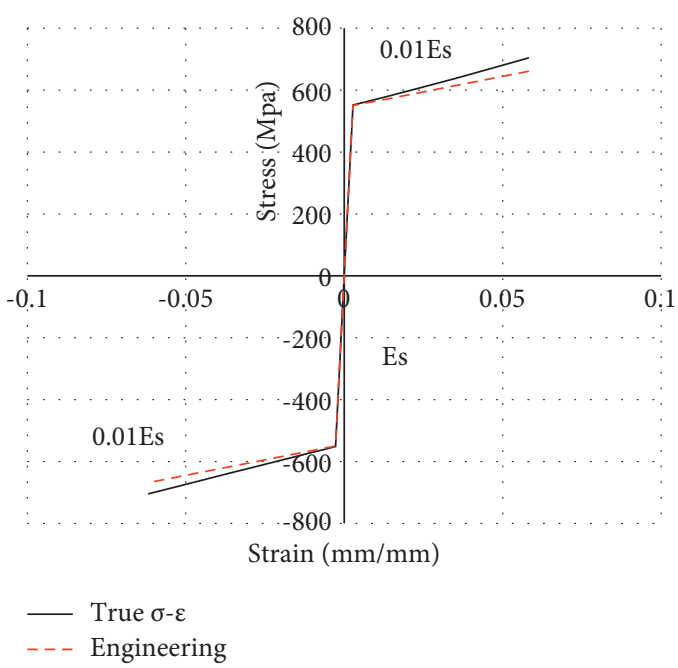

(a)

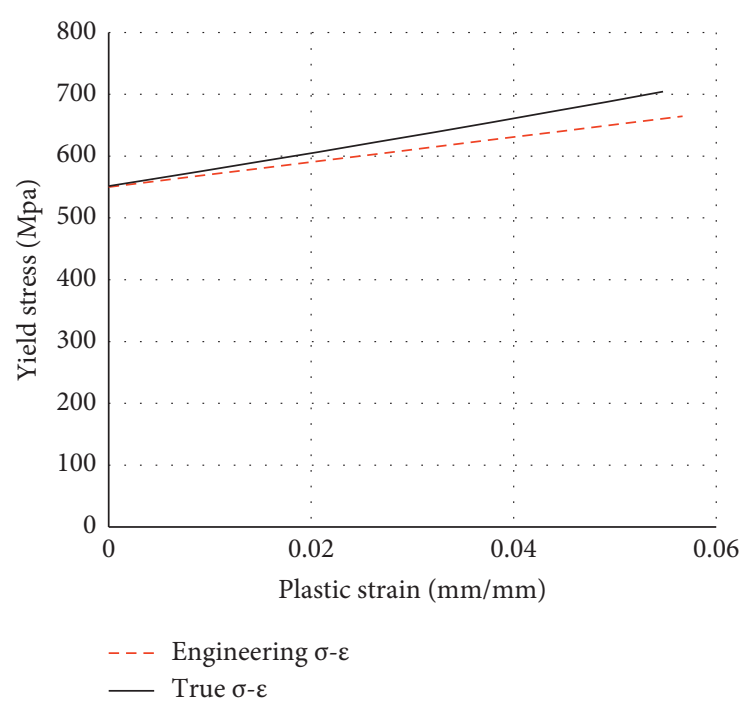

(b)

FIGURE 8: FE analysis steel bars material model. (a) Bilinear stress-strain relation. (b) Yield stress-plastic strain relation.

Figure 11 also demonstrates the failure modes of the FE analysis and the experimental test results at the failure load stage. A good agreement is observed between the failure modes of nonlinear FE analysis and experimental results of the RC column. Overall, these observations indicate that the nonlinear FE simulation using Abaqus/Explicit is a successful tool to predict the behavior of RC columns subjected to dynamic impact load.

\subsection{Parametric Study}

3.2.1. Influence of Impact Velocity. To evaluate the impact load resisting capacity of BRC columns, several nonlinear FE simulations are conducted at different impact velocities. The effects of impact velocity on impact capacity, lateral displacement, and damage modes of both single and repeated impact conditions are examined. As pointed out previously, the velocity of the rigid mass impactor is varied from $10 \mathrm{~m} / \mathrm{s}$ to $25 \mathrm{~m} / \mathrm{s}$. This is based on the vehicle speed limit of our country. While exploring the effects of an impact velocity change on the behaviors of the RC columns, other study parameters including the impact location and axial load are kept constant.

(1) On Impact Capacity. As can be observed in Figure 12(a) and Figure 13(a), in the case of a single impact scenario, the peak impact forces of BRC columns are increasing significantly with the increase of impactor velocity. For example, for two BRC column specimens without axial load, when the impact velocity is $10 \mathrm{~m} / \mathrm{sec}$, the corresponding peak impact force is about $10.29 \mathrm{MN}$. As the impact velocity increases from $10 \mathrm{~m} / \mathrm{sec}$ to $25 \mathrm{~m} / \mathrm{sec}$, the corresponding peak impact force grows from $10.29 \mathrm{MN}$ to $22.1 \mathrm{MN}$, respectively. This is due to an increase of impact energy with impact velocity. It is also observed that compared to normal steel reinforcement distribution, bundling of longitudinal reinforcement bar

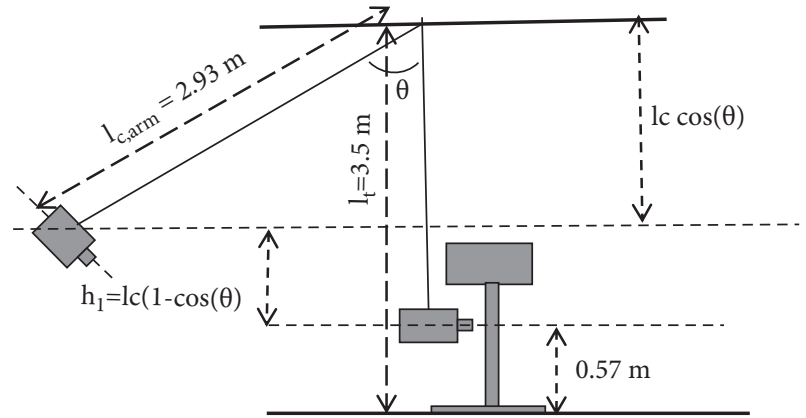

FIGURE 9: Experimental test impact setup.

TABLE 2: Experimental study material properties [14].

\begin{tabular}{lcc}
\hline Material & Input parameter & Magnitude \\
\hline \multirow{4}{*}{ Steel reinforcement } & Mass density $\left(\mathrm{kg} / \mathrm{m}^{3}\right)$ & 7700 \\
& Young's modulus $(\mathrm{GPa})$ & 200 \\
& Poisson's ratio & 0.3 \\
& Yield stress $(\mathrm{MPa})$ & 550 \\
\multirow{2}{*}{ Concrete } & Tangent modulus $(\mathrm{MPa})$ & 1600 \\
& Mass density $\left(\mathrm{kg} / \mathrm{m}^{3}\right)$ & 2400 \\
& Compressive strength $(\mathrm{MPa})$ & 28.3 \\
\hline
\end{tabular}

causes an increase of peak impact force of the RC column with impact velocity.

Figure 12(b) also demonstrates the impact force-time history of BRC columns under repeated impact load with different impact velocities. As it is seen, unlike the single impact condition, the peak impact forces of repeated impact scenarios are not increased with the rise of the impact velocity. It is observed that except for BC-1 RC column specimens, increasing impact velocity led to a decrease of peak impact force. This is due to the fact that in repeated impact scenarios the nonlinear FE dynamic impact analysis includes the effect of residual stress from preceding impact 


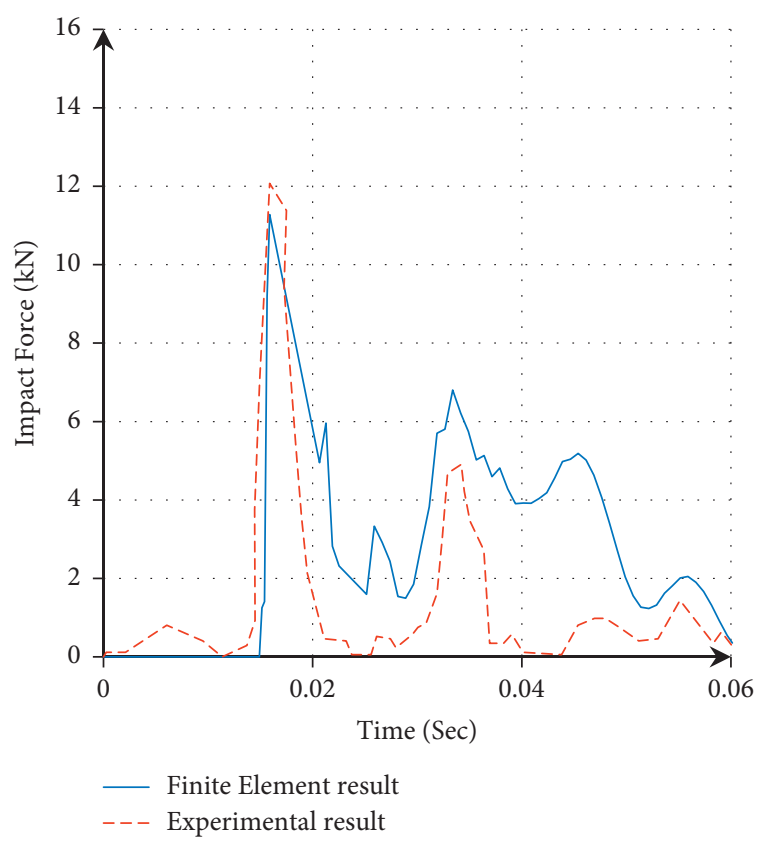

(a)

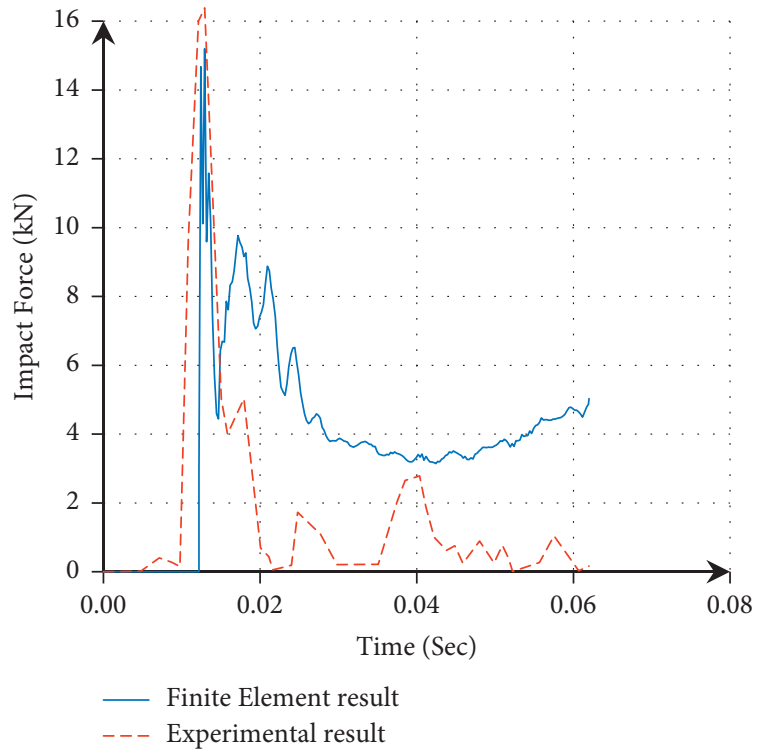

(c)

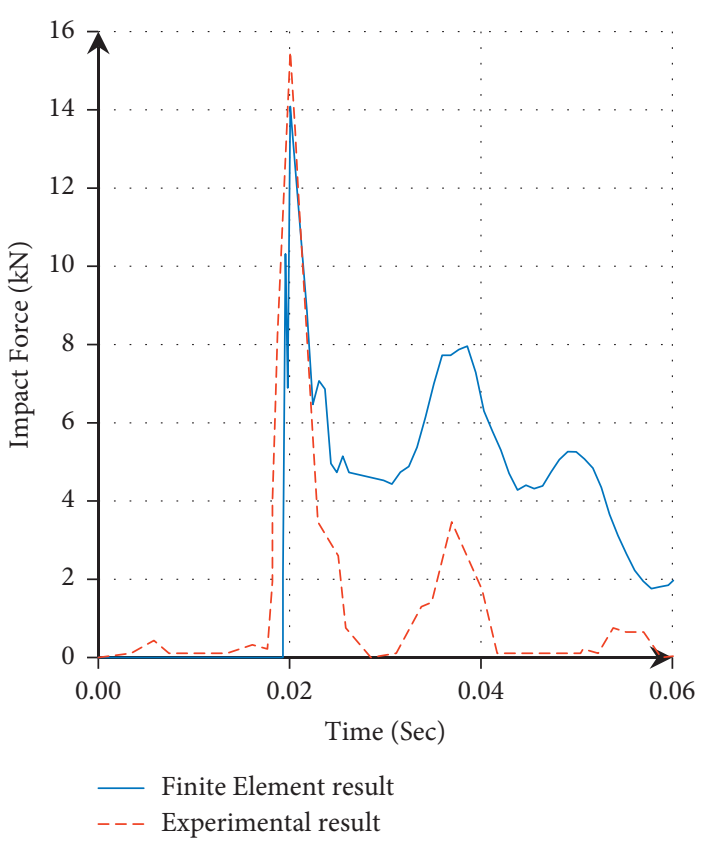

(b)

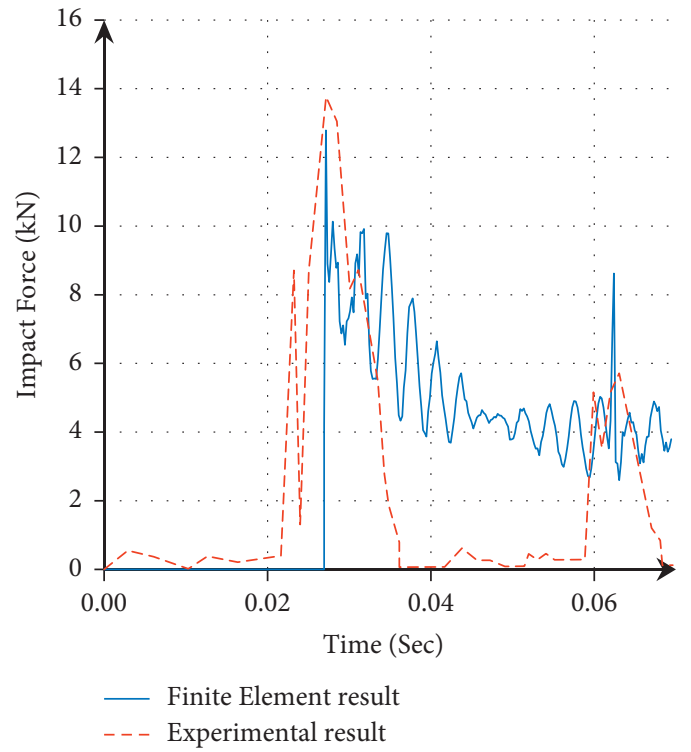

(d)

FIGURE 10: Impact force profile comparisons of experimental and FE analysis results under repeated impact load. (a) First impact. (b) Second impact. (c) Third impact. (d) Fourth impact.

outputs. Therefore, in the case of repetitively impacted BRC columns, increasing the initial impact velocity results in a decrease in the peak impact force until the buckling capacity of the columns is reached.

As shown in Figure 12(a), except for the fourth impact case that has an initial impact velocity of $V_{4}=25 \mathrm{~m} / \mathrm{sec}$, RC column specimens with bundled longitudinal reinforcement responded with high peak impact forces than the column specimens with normal reinforcement distributions. In other words, bundle steel reinforcement bar, especially two bundle systems, has improved the impact response of RC columns. However, single impact analysis overemphasizes the peak buckling force. Since the impact force in a single impact is increased in parallel with an increase of impact velocity, it is difficult to decide the buckling point of the BRC column. Therefore, compared to repeated impact load analysis, this is the main drawback of a single impact scenario.

(2) On Lateral Displacement. The effect of an impact velocity change on the lateral displacement of BRC columns can also be examined in terms of impact force-lateral deflection curves. Figure 13(a) demonstrates the numerical analysis load-deflection relations of different BRC column specimens under the single impact. It can be seen, under a 

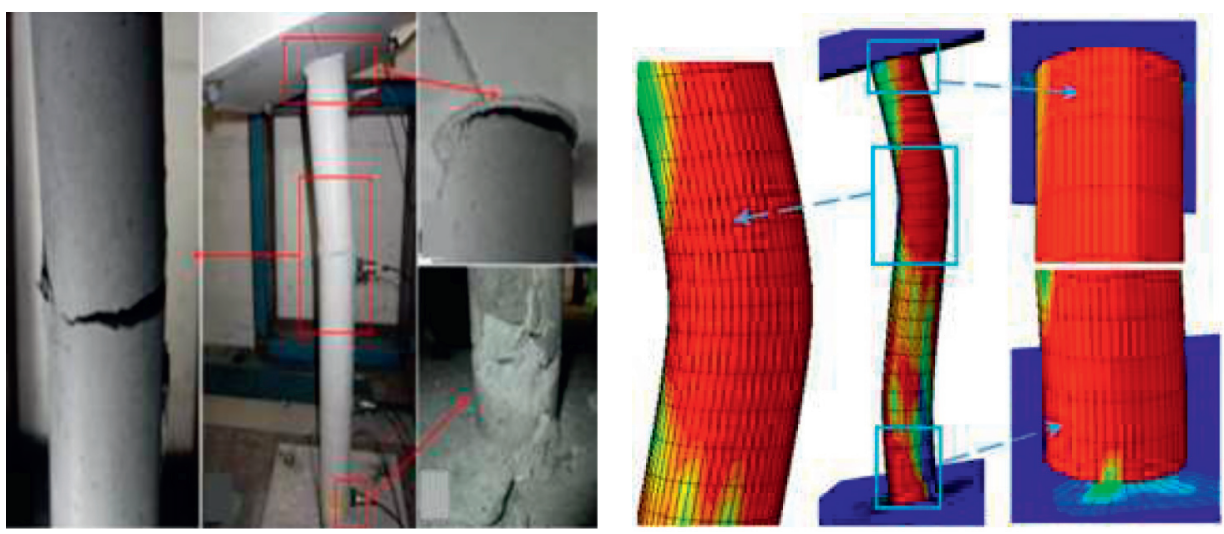

Figure 11: Comparison of damage modes at failure.
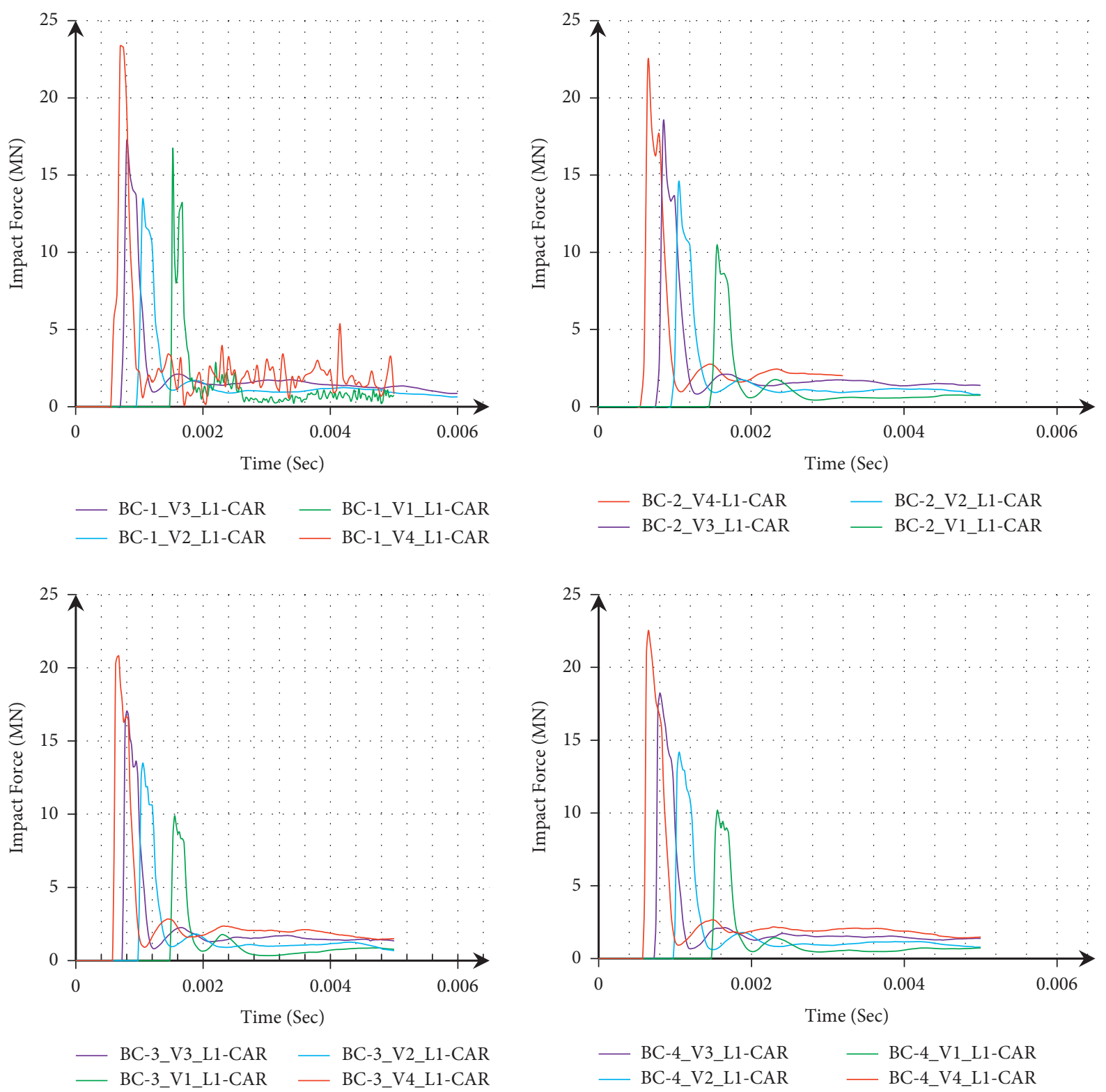

(a)

FIgUre 12: Continued. 


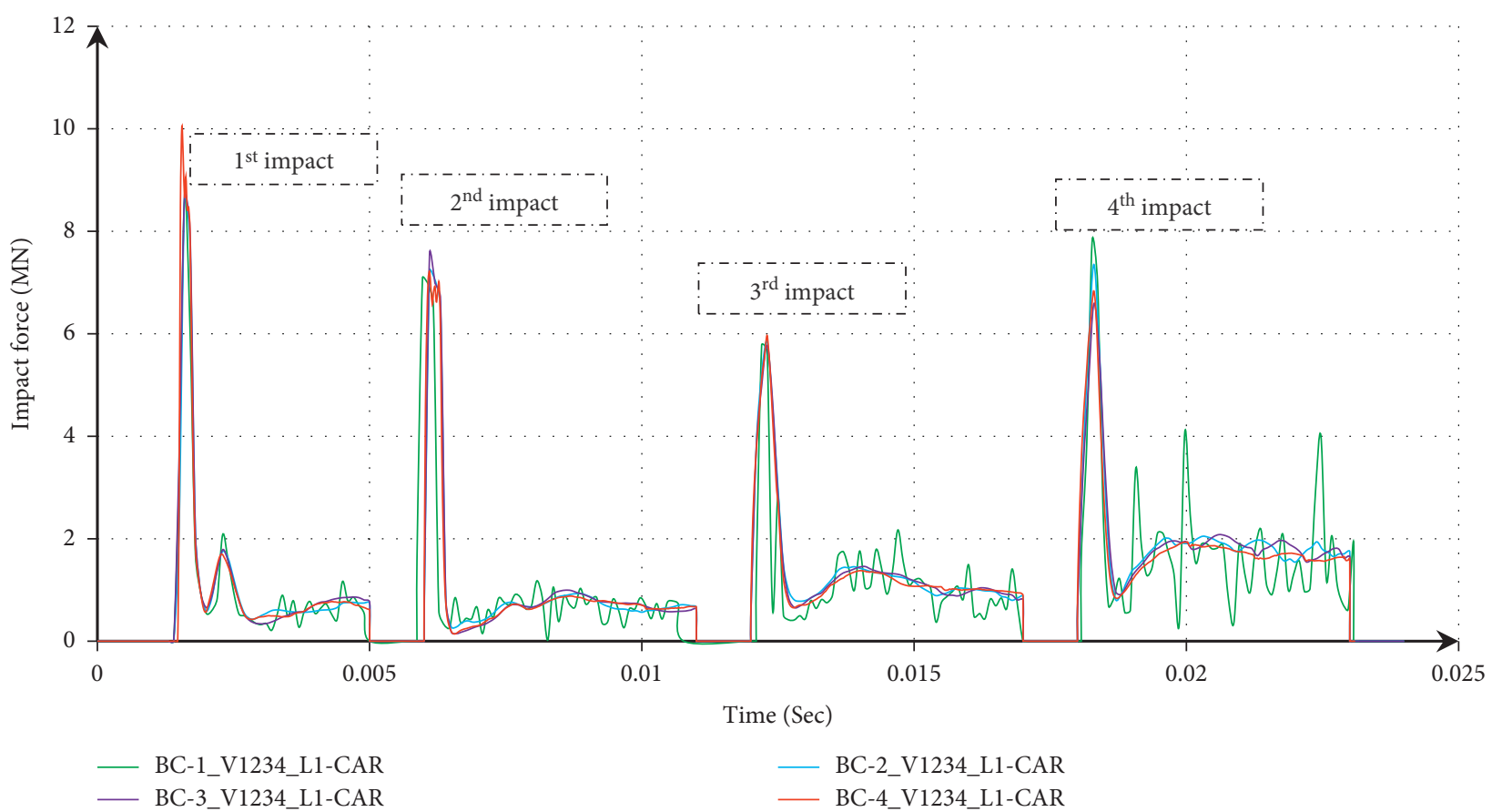

(b)

FIGURE 12: Effect of initial velocity on impact behavior of BRC column. (a) Under single impact load. (b) Under repeated impact load.
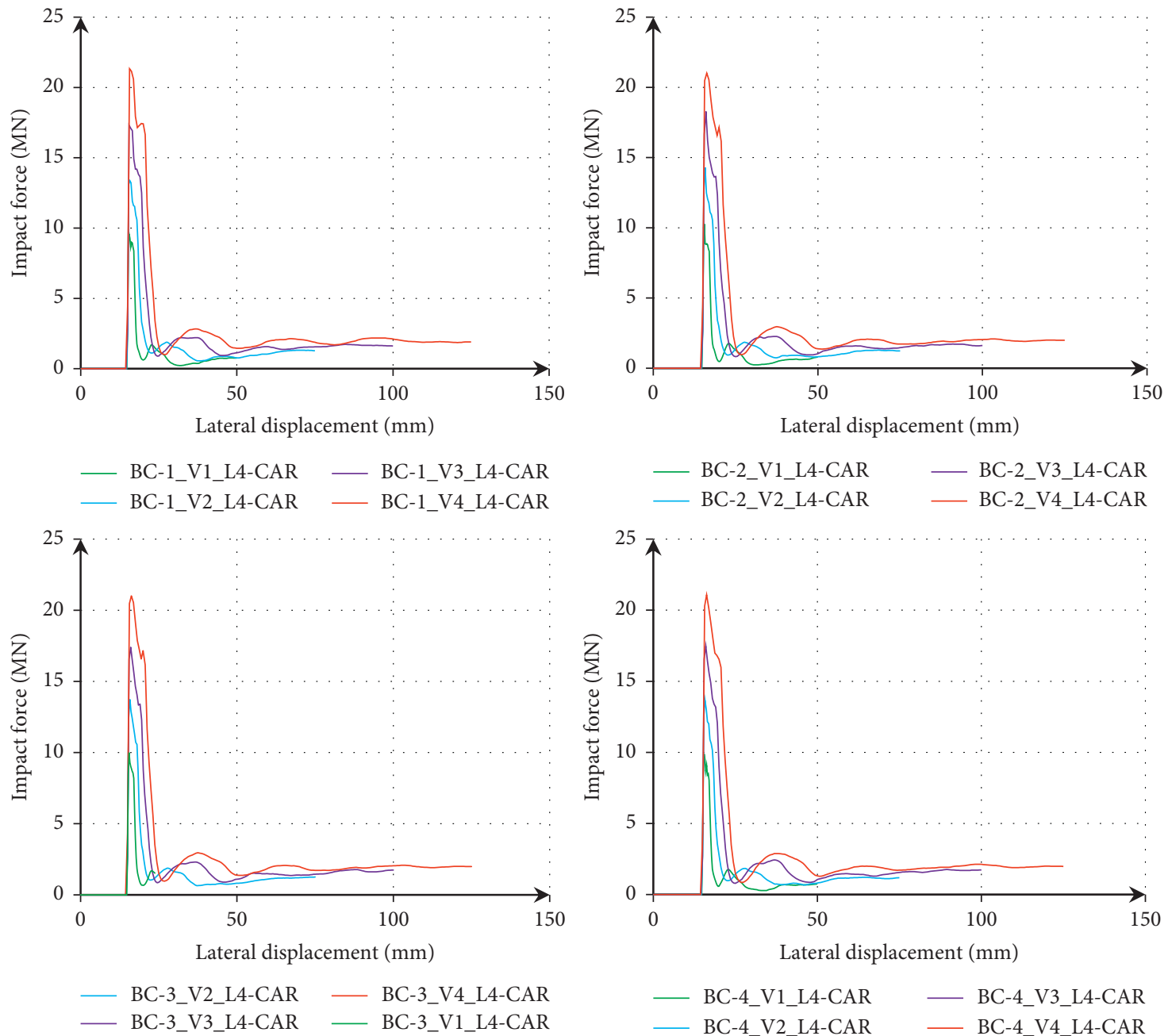

(a)

Figure 13: Continued. 


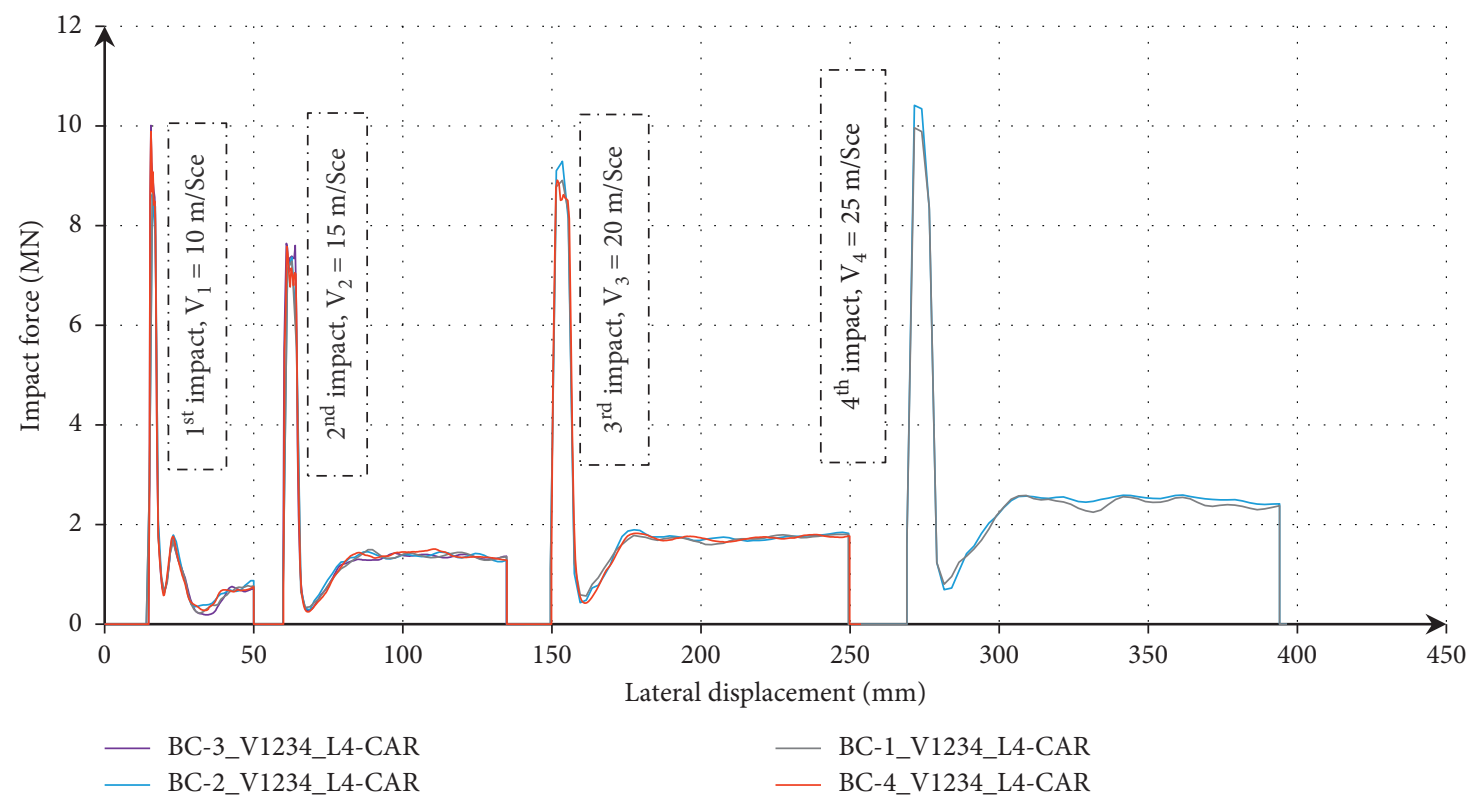

(b)

FIGURE 13: Impact force-lateral displacement curves of BRC columns under variable impact velocity. (a) Single impact scenario. (b) Repeated impact scenario.

single impact, that both the impact force and lateral displacement of impacted column specimens increase with impact velocity. Particularly, the lateral displacement was found to have proportional relation with initial impact velocities. When initial impact velocity increases from $10 \mathrm{~m} / \mathrm{s}$ to $25 \mathrm{~m} / \mathrm{s}$, the corresponding average lateral displacement also upsurges from $50 \mathrm{~mm}$ to $125 \mathrm{~mm}$ correspondingly.

Similar to the single impact scenario, in the case of repeated impact situations, lateral displacement increases with increasing impact velocity. As depicted in Figure 13(b), when the BRC columns were subjected to the first impact velocity of $10 \mathrm{~m} / \mathrm{s}$, the lateral displacement was about $50 \mathrm{~mm}$. As the impact velocity on the subsequent impact conditions increases, the lateral displacement also increases similarly. Finally, when the impact velocity exceeds $25 \mathrm{~m} / \mathrm{s}$, the lateral displacement was more than $400 \mathrm{~mm}$ and the impacted BRC columns were highly damaged with severe shear-dominated failure.

However, under the same impact velocity, the lateral displacement profiles of all bundle RC columns identically coincide. This implies that bundling the longitudinal steel reinforcement bars has no remarkable effects on the lateral displacement of RC columns (refer to Figure 13).

(3) On Damage Mode. In nonlinear FE analysis, the CDP model simulates both tensile and compression behaviors of quasibrittle concrete material [31]. Figures 14(a) and 14(c), respectively, illustrate the compressive and tensile concrete failure modes of BC-2 (i.e., two-bundle system) columns under single impact load with the variability of impact velocity. It is observed that a single impact load with low impact velocity causes local concrete damage of BRC column specimens at the impact zone without any noticeable deformation. In other words, this reveals that the impact energy is smaller than the BRC column impact resistance capacity. When the impact velocity increases from $10 \mathrm{~m} / \mathrm{s}$ to $25 \mathrm{~m} / \mathrm{s}$, the magnitude of concrete material damage tends to increase with shear deformation at the impact location.

Figures 14(b) and 14(d) also show the respective compression and tensile concrete material damage profiles of the same column specimens under repeated impact conditions. The nonlinear FE simulation outputs reveal that the BRC columns subjected to repeated impact load are prone to the global shear flexure failure mechanism. In the case of the first impact (i.e., at $V_{1}=10 \mathrm{~m} / \mathrm{s}$ ) similar to the single impact condition, the BRC columns suffered from local damage at the impact location. However, on subsequent impact conditions, significant destruction of concrete material in both tension and compression is observed by shifting from the local shear to global shear flexure failure mode. Moreover, even if the severity of damage in both conditions increases with the increase of impact velocity, compared to a single impact condition, the repetitively impacted BRC columns suffered rapidly. This may be because of the consequence of stored unbalanced residual stresses from the previous impacts.

3.2.2. Influence of Axial Load. Figure 15 exemplifies the effect of pure axial load magnitude change on single impacted BRC column specimens. To understand the effect clearly, during comparison, the initial impact velocity of all bundled reinforced concrete columns is chosen as $15 \mathrm{~m} / \mathrm{sec}$, while the axial load is varied from $0 \mathrm{kN}$ to $3000 \mathrm{kN}$ (i.e., $0 \%$ to $42 \%$ of the column capacity). 


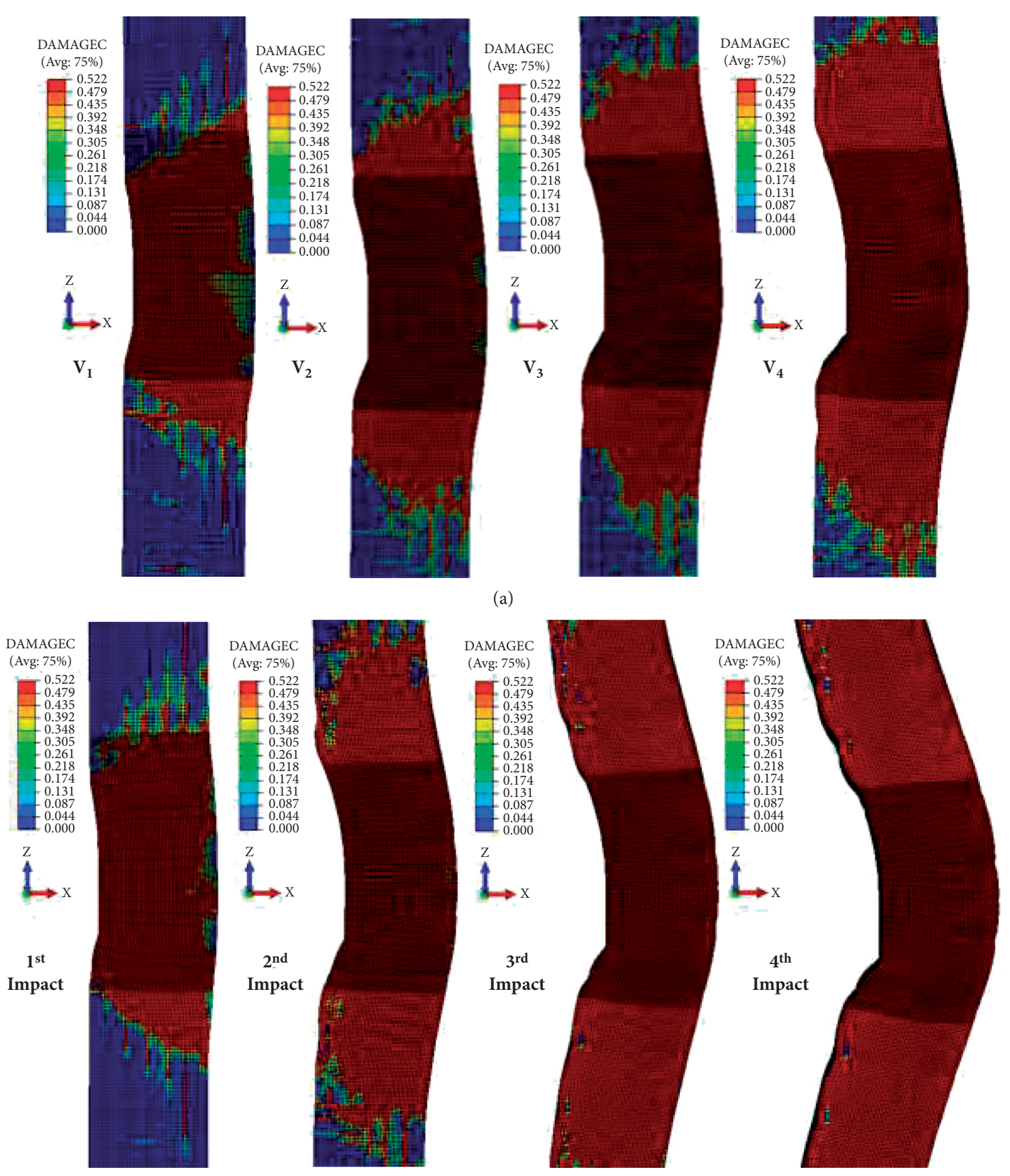

(b)

Figure 14: Continued. 

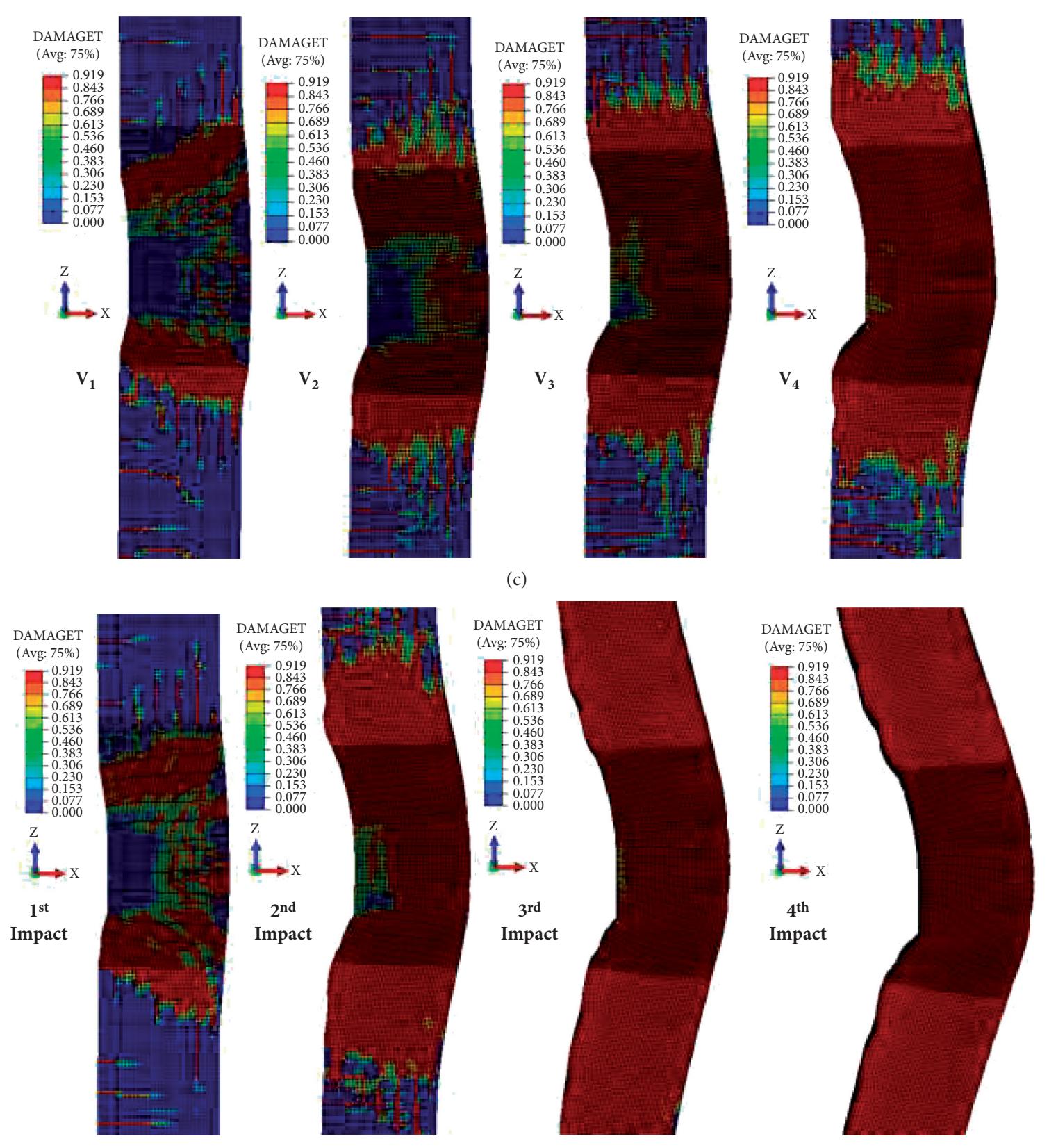

(d)

Figure 14: Concrete damage modes of BC-2 at different impact velocities. (a) Compression damage under a single impact. (b) Compression damage under repeated impact. (c) Tensile damage due to single impact. (d) Tensile damage due to repeated impact.

At low impact energy, researchers had observed that axial load has a positive influence on the impact capacity of RC columns $[7,16,17]$. However, in this study, as can be observed in Figure 15, although the peak impact forces of single impacted BRC columns increase slightly with increasing axial load, the impact force-time histories of each specimen in every bundle group were about the same. This may be because of the high impact velocities that led to high impact energy and cantilever action (axial deformation is allowed) of the RC columns. As well, compared to other group specimens with various bundle reinforcement distributions, it seems that group 2 and group 3 specimens have noteworthy improvements of peak impact force. In particular, two-bundle reinforced concrete column specimens (i.e., BC-2) show high peak impact force. Compared to group 1 (BC-1), it was found that group 2 (BC-2) specimens show an average of about $7 \%$ increments of the peak impact force; see Figures 15(a) and 15(b). This clarifies that bundle reinforcement has a positive effect on the impact response of the RC column.

Figure 16 demonstrates the effect of axial load on the impact behavior of repetitive impacted BRC columns. Similar to single impacted column specimens, to evaluate the effect of axial load variation on repeated impact responses of BRC 

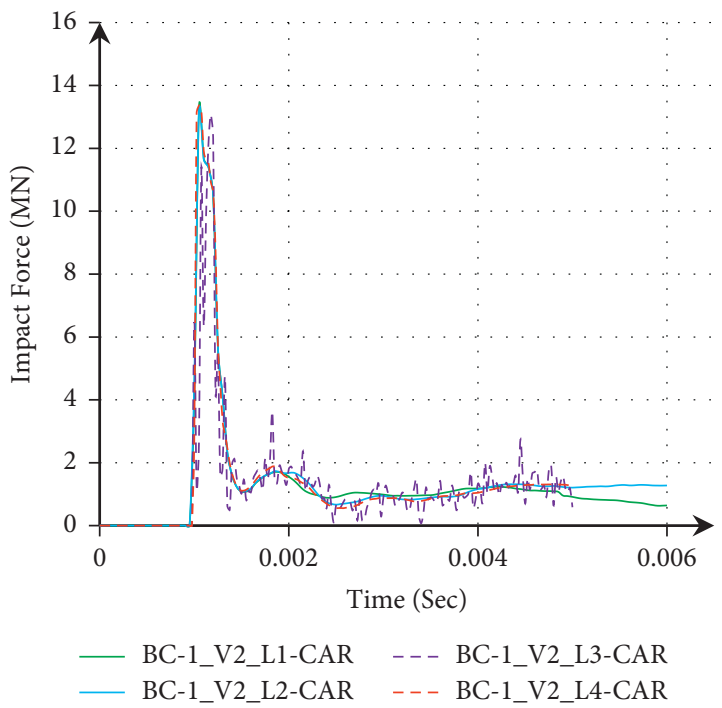

(a)

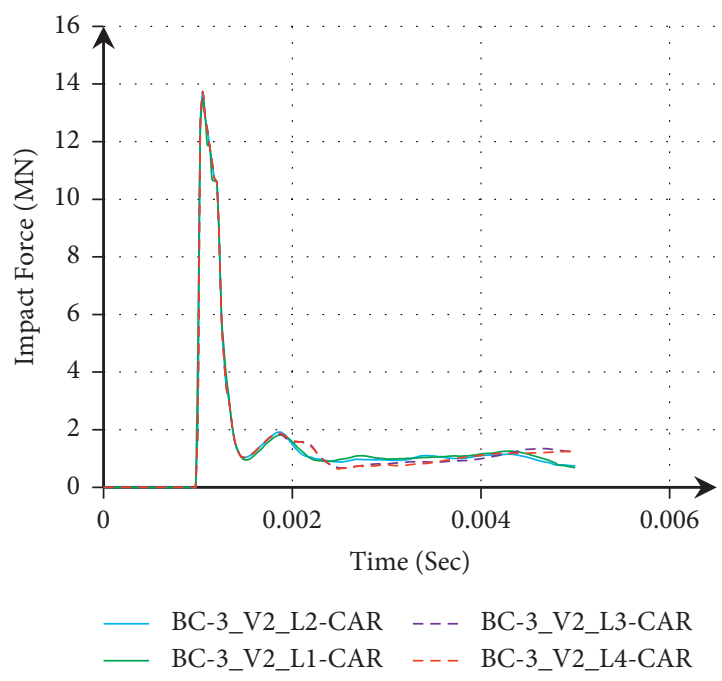

(c)

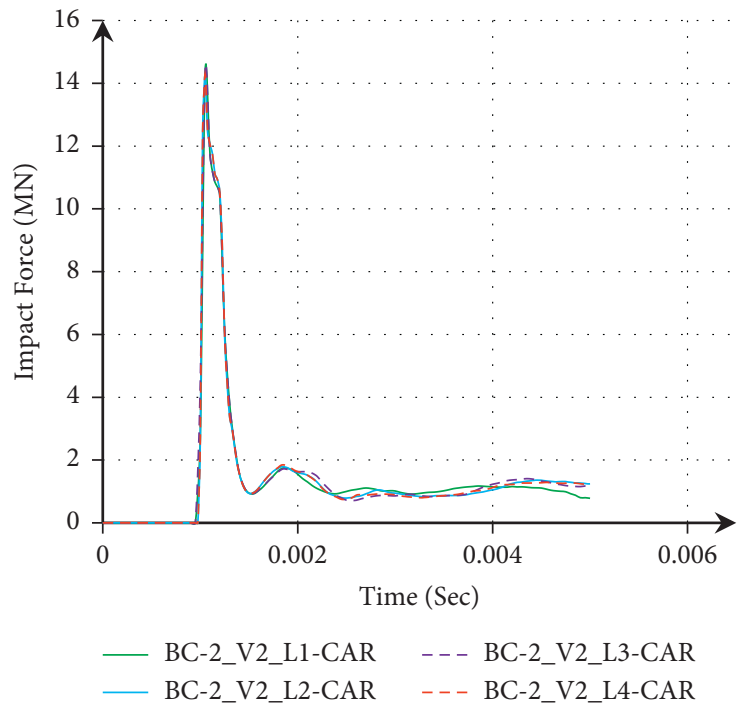

(b)

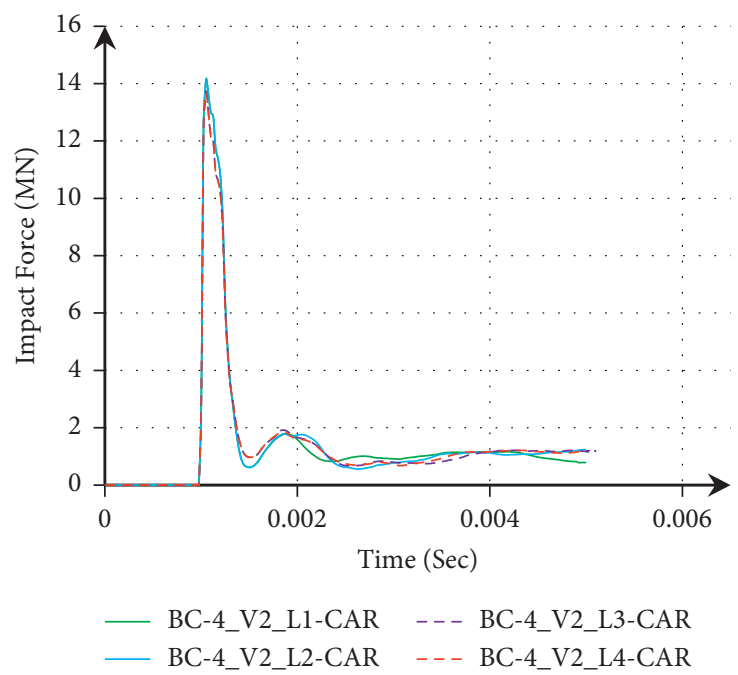

(d)

FIgURE 15: Effect of axial load on single impact capacity of BRC columns. (a) Without bundling (BC-1). (b) Two-bundle system (BC-2). (c) Three-bundle system (BC-3). (d) Four-bundle system (BC-4).

columns, four axial loads with magnitudes of $0 \%, 14 \%, 21 \%$, and $42 \%$ of RC column capacity are employed. As shown in Figures 16(a) to 16(d), even if it was not significant, the increase of axial load generated a minor increase of peak impact force. However, compared to group 2, 3, and 4 specimens, it was found that for group 1 specimens a decrease in axial load led to fluctuated impact response; see Figure 16(a). This may be due to the fore and back vibration of the column after being struck with the impactor. Conversely, it appears that increasing axial load solves this disturbance of column impact reaction. Overall, an increase of pure axial load slightly improves the impact capacity of the BRC column.

3.2.3. Influence of Impact Location. Figures 17 (a) to $17(\mathrm{~d})$ illustrate the impact force-time history of different BRC column models with mutable impactor locations, denoted as
$\mathrm{L} 2$ and $\mathrm{L} 2 \mathrm{M}$ for $1.2 \mathrm{~m}$ and $1.5 \mathrm{~m}$, respectively, from the column base. As can be seen in Figures 17(a) to 17(d), the peak impact forces of the central impacted column are higher than the near-end impact. Also, as compared to the central impact, the impact condition at $1.2 \mathrm{~m}$ of group 1 specimens revealed some fluctuated impact force curves; see Figure 17(a). This variable response of near-end impacted $\mathrm{RC}$ column may arise because of the unstable column vibration during impact. This result was consistent with the previous study conducted by Malhotra and Guild [32].

Moreover, from the dynamic response of impacted BRC columns at different impact locations, it was found that columns with bundle reinforcement have greater peak impact force than the columns with uniform reinforcement distribution. Of all BRC column specimens, maximum peak impact forces were found for group 2 (i.e., two bundle system) columns impacted at the center of the column. 


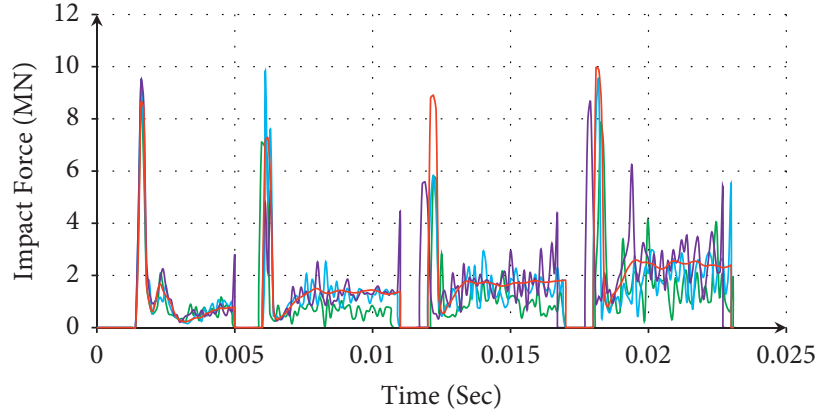

BC-1_V1234_L1-CAR - BC-1_V1234_L2-CAR
BC-1_V1234_L3-CAR - BC-1_V1234_L4-CAR

(a)

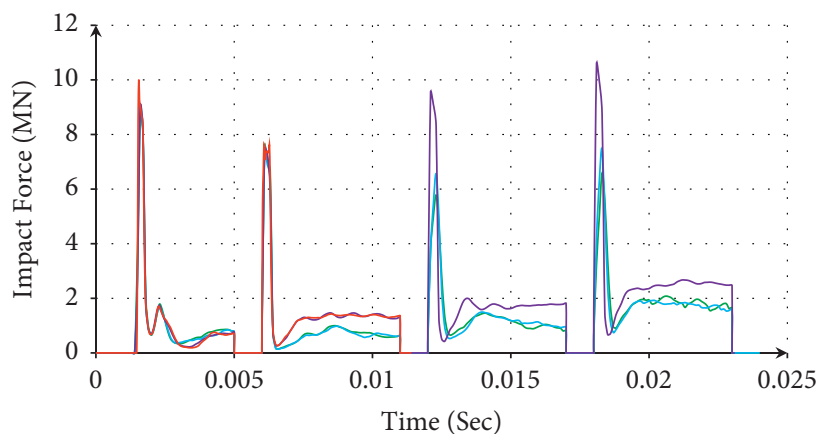

- BC-3_V1234_L1-CAR - BC-3_V1234_L2-CAR

- BC-3_V1234_L3-CAR - BC-3_V1234_L4-CAR

(c)

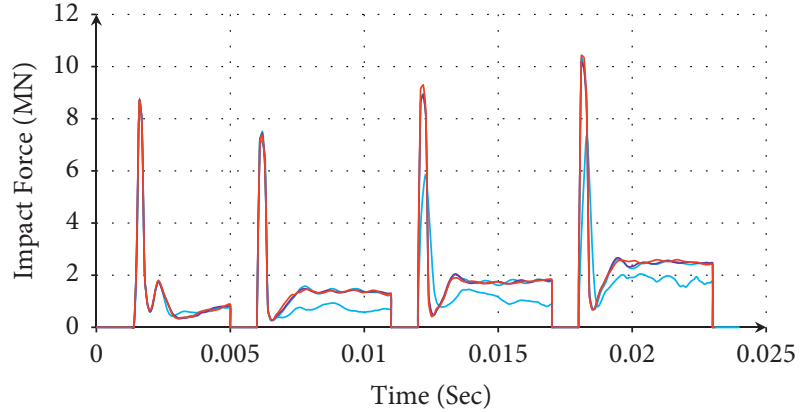

- BC-2_V1234_L1-CAR — BC-2_V1234_L2-CAR

- BC-2_V1234_L3-CAR - BC-2_V1234_L4-CAR

(b)

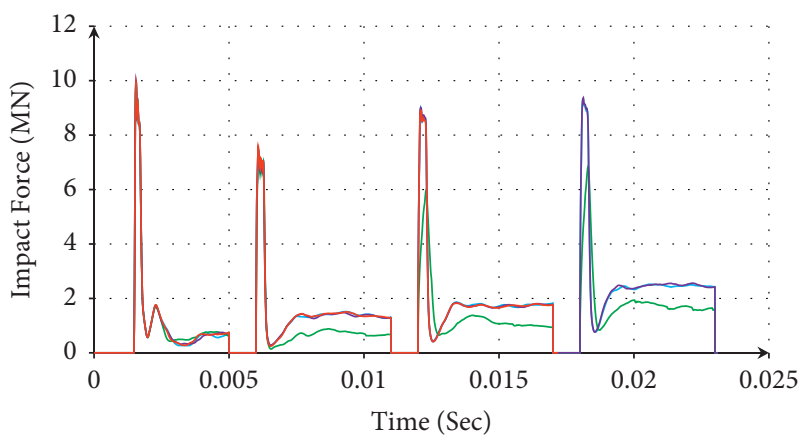

-BC-4_V1234_L2-CAR — BC-4_V1234_L1-CAR

— BC-4_V1234_L3-CAR — BC-4_V1234_L4-CAR

(d)

FIGURE 16: Effect of axial load on repetitively impacted BRC columns. (a) Normal reinforcement distribution without bundling (BC-1). (b) Two-bundle reinforcement distribution (BC-2). (c) Three-bundle reinforcement distribution (BC-3). (d) Four-bundle reinforcement distribution (BC-4).

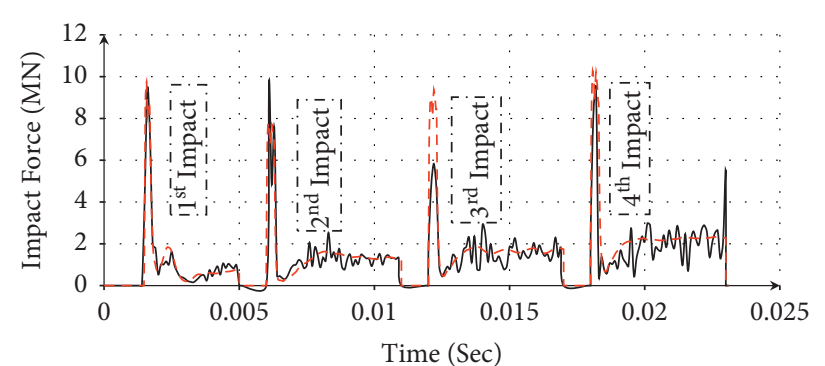

$\begin{array}{ll}- & \text { BC-1_V1234_L2-CAR } \\ -- & \text { BC-1_V1234_L2M-CAR }\end{array}$

(a)

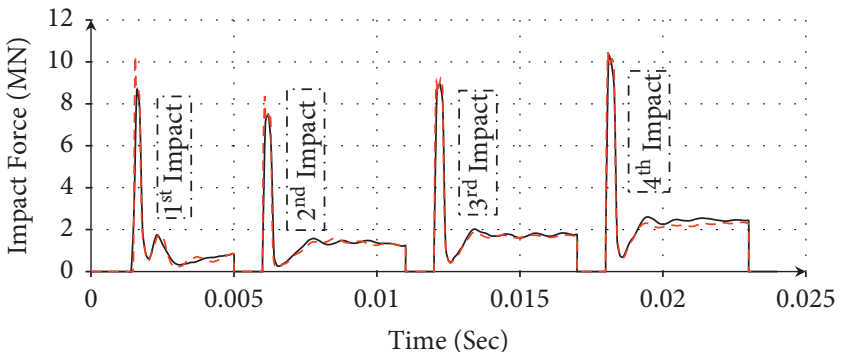

- BC-2_V1234_L2-CAR

(b)

Figure 17: Continued. 


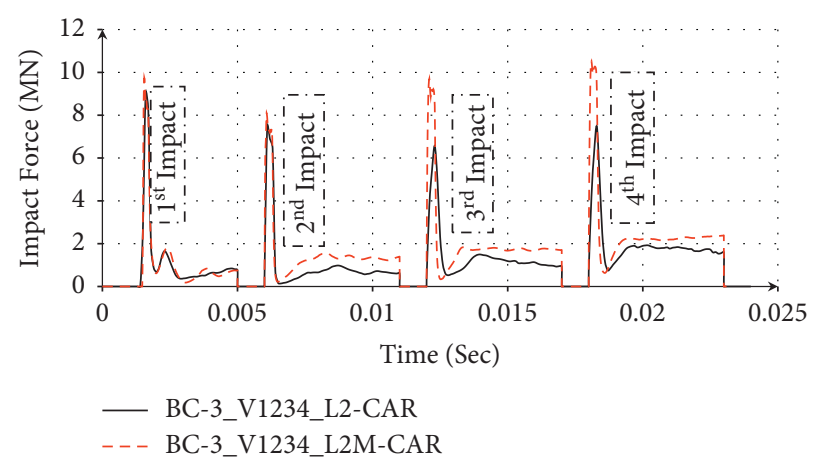

(c)

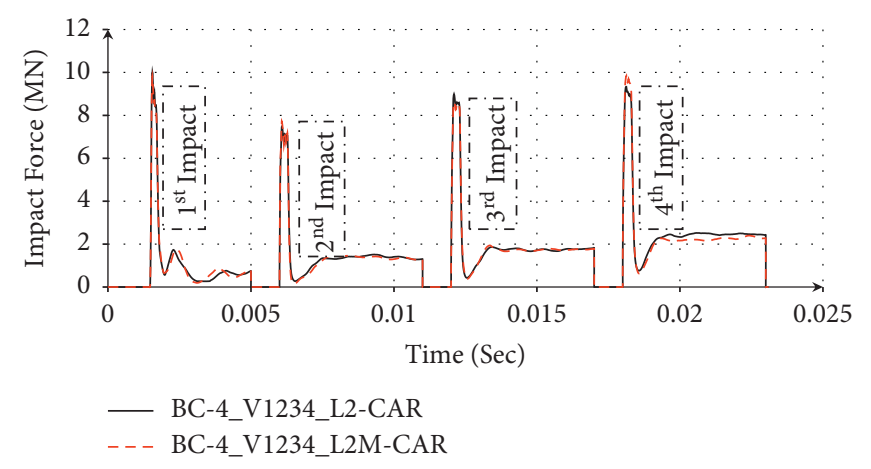

(d)

FIGURE 17: Influence of impact location on impact behavior of BRC columns. (a) Without bundle reinforcement distribution. (b) Twobundle reinforcement distribution. (c) Three-bundle reinforcement distribution. (d) Four-bundle reinforcement distribution.

Generally, from the two impact locations, it can be concluded that central impacted RC columns with two-bundle reinforcement distribution (BC_2) have higher lateral impact capacity.

\section{Conclusion}

This study is aimed at numerical investigation of bundle reinforced concrete columns subjected to the lateral impact. After validating the numerical models with previous experimental tests conducted by Sha and Yanyan [14], different parametric studies were carried out to understand comprehensively the behavior of BRC columns under both single and repetitive impact loads. The following conclusions can be made:

(i) It was found that the lateral impact load response of $\mathrm{RC}$ pier generated from nonlinear FE analysis shows good agreement with the previous experimental test of the same member. Although there are some inconsistencies of impact force-time history beyond the peak value, overall it is suitable to predict the impact response of the RC column.

(ii) The dynamic nonlinear FE analysis responses of laterally impacted BRC columns indicated that with increasing impact velocity the peak impact force and the maximum transverse displacement of BRC columns have also increased.

(iii) Increasing pure axial load from $0 \%$ to $42 \%$ of column capacity led to a slight improvement in the impact performance of the laterally impacted BRC column. However, the axial load has no remarkable effect on the lateral displacements and damage modes of medium velocity impacted BRC columns.

(iv) Also, nonlinear FE analysis results of the examined RC columns have revealed that bundling of longitudinal reinforcement bars has a positive effect on the lateral impact performance of RC columns. Under the same impact velocity and axial load, bundled RC columns showed high peak impact force over the normally reinforced concrete columns. Bundle steel reinforcement also stabilizes the vibration disturbance that happened on RC columns without bundle bar. Overall, bundle longitudinal steel reinforcement bar, mainly two bundle systems, improved the impact capacity of the RC column.

(v) In single impact nonlinear FE analysis, the impact force increases in parallel with the increase of impact velocity. This overemphasizes the peak impact force of the laterally impacted BRC columns. In contrast during repeated impact, because of residual stress from the preceding impact, the peak impact force decreases with increasing impact velocity. Therefore, compared to repeated impact analysis, it is difficult to decide the buckling point of a single impacted BRC column.

\section{Abbreviations}

$\mathrm{RC}:$

BRC:

FE:

CDP, SCM, Concrete damaged plasticity, smeared

BCM:

$\dot{\varepsilon}, \dot{\varepsilon}^{e l}, \dot{\varepsilon}^{p l}:$

Reinforced concrete

$\varepsilon, \varepsilon^{e l},^{e l} \sim^{p l}$ Total, elastic, and plastic strain rates

concrete tensile strains $(\mathrm{mm} / \mathrm{mm})$

$D_{o}^{e l}, D^{e l}: \quad$ Initial (undamaged) elastic stiffness, degraded elastic stiffness (MPa)

$\sigma_{c}, \sigma_{t}: \quad$ Compressive, tensile concrete stresses

$(\mathrm{MPa})$

$\widetilde{\varepsilon}_{c}^{i n}, \varepsilon_{t}^{c k}: \quad$ Inelastic strain, cracking strain $(\mathrm{mm} / \mathrm{mm})$

$\varepsilon_{c 1}, \varepsilon_{c u 1}$ : $\quad$ Strain at peak stress, nominal ultimate strain $(\mathrm{mm} / \mathrm{mm})$

$d_{t}, d_{c}$ : Tensile, compressive concrete stiffness

degradation variables

$f_{\mathrm{ct}}, f_{\mathrm{cm}}$ : Uniaxial tensile, mean compressive concrete strengths $(\mathrm{MPa})$.

\section{Data Availability}

The editable Excel files of study results are included within the figure files. In addition, data used to support the findings 
of this study are available from the corresponding author upon request.

\section{Disclosure}

The authors are responsible for the content and writing of this article.

\section{Conflicts of Interest}

The authors declare that there are no known conflicts of interest.

\section{Acknowledgments}

The authors would like to acknowledge the Addis Ababa Science and Technology University (AASTU) Mining Engineering Department Head for providing support to perform the FE simulation of the study. This research did not receive any specific grant from funding agencies but was made as partial fulfillment of the requirements for the award of Master of Science in structural engineering.

\section{References}

[1] L. Deng, W. Yan, and L. Nie, "A simple corrosion fatigue design method for bridges considering the coupled corrosionoverloading effect," Engineering Structures, vol. 178, pp. 309-317, 2019.

[2] N. H Yi, J. H Choi, S. J Kim, and J. H. J Kim, "Collision capacity evaluation of RC columns by impact simulation and probabilistic evaluation," Advanced Concrete Technology, vol. 13, no. 2, pp. 67-81, 2015.

[3] X. R. Zhang and R. C. Yu, "A New Drop-Weight Impact Machine for Studying Fracture Processes in Structural Concrete," Strain, vol. 46, no. 3, pp. 252-257, 2008.

[4] Z. Sun, L. Fu, De-C. Feng, A. R. Vatuloka, W. Yang, and $\mathrm{G}$. Wu, "Experimental Study on the Flexural Behavior of concrete Beams Reinforced with Bundled Hybrid Steel/FRP Bars," Engineering Structures, vol. 197, Article ID 109443, 2019.

[5] S. Argaw, Numerical Simulation of Moment and Lateral Load Resisting Capacity of Rectangular Reinforced Concrete Column with Bundle Bars, Msc, Addis Ababa Institute of Technology (AAiT), Addis Ababa, Ethiopia, 2018.

[6] W. Wang and G. Morgenthal, "Dynamic analyses of square RC pier column subjected to barge impact using efficient models," Engineering Structures, vol. 151, pp. 20-32, 2017.

[7] B. Liu, W. Fan, W. Guo, B. Chen, and R. Liu, "Experimental investigation and improved FE modeling of axially-loaded circular RC columns under lateral impact loading," Engineering Structures, vol. 152, pp. 619-642, 2017.

[8] J. Cai, J.-B. Ye, Q.-J. Chen, X. Liu, and Y.-Q. Wang, "Dynamic behaviour of axially-loaded RC columns under horizontal impact loading," Engineering Structures, vol. 168, pp. 684-697, 2018.

[9] T. Warakorn and H. Chayanon, "Impact response of reinforced concrete columns with different axial load under lowvelocity impact loading," Key Engineering Materials, vol. 803, pp. 322-330, 2019.

[10] W. Fan, B. Liu, X. Huang, and Y. Sun, "Efficient modeling of flexural and shear behaviors in reinforced concrete beams and columns subjected to low-velocity impact loading," Engineering Structures, vol. 195, pp. 22-50, 2019.

[11] W. Fan, B. Liu, and G. R. Consolazio, "Residual capacity of axially loaded circular RC columns after lateral low-velocity impact," Journal of Structural Engineering, vol. 145, no. 6, Article ID 04019039, 2019.

[12] C. Demartino, J. G. Wu, and Y. Xiao, "Response of sheardeficient reinforced circular RC columns under lateral impact loading," International Journal of Impact Engineering, vol. 109, pp. 196-213, 2017.

[13] V. D. Tin, T. M Pham, and H. Hong, "Proposed design procedure for reinforced concrete bridge columns subjected to vehicle collisions," Structure, vol. 22, pp. 213-229, 2019.

[14] Y. Sha and H. Hong, "Laboratory tests and numerical simulations of CFRP strengthened RC pier subjected to barge impact load," International Journal of Structural Stability and Dynamics, vol. 15, p. 33, 2014.

[15] H. Dabbagh and A. Nosoudi, "Nonlinear finite element modeling of different cross-sectional shapes of slender RC columns confined with CFRP wraps," J Journal of Rehabilitation in Civil Engineering, vol. 6, no. 2, pp. 58-81, 2018.

[16] I. Paul, Response of Reinforced concrete Columns Subjected to Impact Loading, Université d'Ottawa/University of Ottawa, Ottawa, Canada, 2012.

[17] R. Xie, W. Fan, B. Liu, and D. Shen, "Dynamic behavior and vulnerability analysis of bridge columns with different crosssectional shapes under rockfall impacts," Structure, vol. 26, pp. 471-486, 2020.

[18] Y. Xiao, B. Li, and K. Fujikake, "Behavior of reinforced concrete slabs under the low-velocity impact," ACI Structural Journal, vol. 114, no. 3, p. 643, 2017.

[19] J. Cai, J. Ye, Y. Wang, and Q. Chen, "Numerical study on dynamic response of reinforced concrete columns under lowspeed horizontal impact loading," Procedia Engineering, vol. 210, pp. 334-340, 2017.

[20] D. S. Simulia, Abaqus 2017, Documentation, Dassault Systemes Waltham, Waltham, Massachusetts, 2017.

[21] B. H. A. Algohi, "An experimental and numerical study of retrofitted masonry walls under cyclic loading," Civil \& Environmental Engineering, King Fahd University of Petroleum \&Minerals, Dhahran, Saudi Arabia, Ph.D. thesis, pp. 1-24, 2013.

[22] British Standards Institution, The European Standard EN 1992-1-1: 2004 Eurocode 2: Design of concrete Structures, BSI London, London, UK, 2004.

[23] S. Popovics, "A numerical approach to the complete stressstrain curve of concrete," Cement and Concrete Research, vol. 3, no. 5, pp. 583-599, 1973.

[24] E. Hognestad, N. W. Hanson, and M. C. H. Douglas, "Concrete stress distribution in ultimate strength design," Journal Proceedings, vol. 52, no. 12, pp. 455-480, 1955.

[25] D. Prakash and S. Krishnan, "Equation for the stress-strain curve of concrete," Journal Proceedings, vol. 61, no. 3, pp. 345-350, 1964.

[26] D. J. Carreira and K.-H. Chu, "Stress-strain relationship for plain concrete in compression," Journal Proceedings, vol. 82, no. 6, pp. 797-804, 1985.

[27] D. A. Hordijk and J. Heron, "Tensile and tensile fatigue behavior of concrete," Experiments, Modeling, and Analyses, vol. 37, no. 1, pp. 1-79, 1992.

[28] J. C. Walraven and Model CEB-FIP code, Model Code 2010 Final draft, Volume 1, Vol. 2, International Federation for Structural Concrete (fib), Lausanne, Switzerland, 2010. 
[29] D. I. Kachlakev, T. H. Miller, T. Potisuk, S. C. Yim, and K. Chansawat, "Finite element modeling of reinforced concrete structures strengthened with FRP laminates," Oregon Department of Transportation, Research Group, Salem, OR, United States, Final Report, p. 130, 2001.

[30] L. J. Malvar and C. A. Ross, "Review of strain rate effects for concrete in tension," ACI Materials Journal, vol. 95, pp. 735-739, 1998.

[31] C. Abaqus, Analysis User's Manual, 2017.

[32] A. Malhotra and F. J. Guild, "Impact damage to composite laminates: effect of impact location," Applied Composite Materials, vol. 21, no. 1, pp. 165-177, 2014. 